Review Article

\title{
Uniparental genetic markers in South Amerindians
}

\author{
Rafael Bisso-Machado, Maria Cátira Bortolini and Francisco Mauro Salzano \\ Departamento de Genética, Instituto de Biociências, Universidade Federal do Rio Grande do Sul, \\ Porto Alegre, RS, Brazil.
}

\begin{abstract}
A comprehensive review of uniparental systems in South Amerindians was undertaken. Variability in the Y-chromosome haplogroups were assessed in 68 populations and 1,814 individuals whereas that of Y-STR markers was assessed in 29 populations and 590 subjects. Variability in the mitochondrial DNA (mtDNA) haplogroup was examined in 108 populations and 6,697 persons, and sequencing studies used either the complete mtDNA genome or the highly variable segments 1 and 2 . The diversity of the markers made it difficult to establish a general picture of Y-chromosome variability in the populations studied. However, haplogroup Q1a3a* was almost always the most prevalent whereas Q1a3* occurred equally in all regions, which suggested its prevalence among the early colonizers. The STR allele frequencies were used to derive a possible ancient Native American Q-clade chromosome haplotype and five of six STR loci showed significant geographic variation. Geographic and linguistic factors moderately influenced the mtDNA distributions ( $6 \%$ and $7 \%$, respectively) and mtDNA haplogroups A and D correlated positively and negatively, respectively, with latitude. The data analyzed here provide rich material for understanding the biological history of South Amerindians and can serve as a basis for comparative studies involving other types of data, such as cultural data.
\end{abstract}

Key words: genetics, language and geography, mitochondrial DNA, Native Americans, South Amerindians, Y-chromosome.

Received: September 23, 2011; Accepted: January 12, 2012.

\section{Introduction}

Native Americans have been the subject of a large number of population genetic studies because of particular characteristics: (a) there are groups among them that until recently had a hunter-gatherer way of living with only incipient agriculture, typical of our ancestors, (b) they show considerable interpopulation but low intrapopulation variability, and (c) since until recently they could not write there is no written record of their history, except for those of non-Amerindian colonizers. Biological studies can therefore be used to investigate their past.

The first genetic studies examined the variability in blood groups and proteins and have been summarized in Salzano and Callegari-Jacques (1988) and Crawford (1998). The advent of modern molecular biology, which allows direct, detailed DNA analysis, has opened new possibilities for investigating these populations.

DNA studies can basically be divided into two groups: those involving autosomal markers and those involving uniparental (Y-chromosome, mitochondrial DNA) markers. The latter are important because they can provide

Send correspondence to Francisco M. Salzano. Departamento de Genética, Instituto de Biociências, Universidade Federal do Rio Grande do Sul, Caixa Postal 15053, 91501-970, Porto Alegre, RS, Brazil. E-mail: francisco.salzano@ufrgs.br. a clear-cut pattern of historical events that is not clouded by recombination factors. For Amerindians, the number of reviews that have dealt with these markers is not large or comprehensive. For the Y-chromosome, Bortolini et al. (2003) considered 438 individuals from 23 Southern and one Northern Amerindian populations who were screened for eight single nucleotide polymorphisms (SNPs) and six short tandem repeat/microsatellite (STR) loci, and Zegura et al. (2004) studied 63 binary polymorphisms and 10 STR regions in 2,344 persons from 15 Northern and three Southern Amerindian groups. Only a few recent studies have used all known SNPs necessary to identify the major Native American Y-haplogroups and their sublineages in Amerindian populations (Geppert et al., 2011; Jota et al., 2011; Bisso-Machado et al., 2011).

The most recent mtDNA reviews were published four years ago and involved sequence variability in the hypervariable region 1 (Hunley et al., 2007; Lewis Jr et al., 2007). Schurr and Sherry (2004), on the other hand, associated data from Y-chromosome markers with mitochondrial DNA (mtDNA) results, providing a good picture of the information available at the time. No general review considering both data sets has been published since then.

This review provides a detailed, comprehensive survey of Y-chromosome haplogroup frequency variation in 68 populations involving 1,814 individuals. In addition, 
specific information on Y-STR markers for 29 populations and 590 subjects is given. The haplogroup mtDNA data included 108 populations involving a total of 6,697 persons. Geographic and linguistic factors that may have influenced this variation were carefully considered, leading to a global, overview of the genetic pattern associated with these markers in South Amerindians. Information on mtDNA sequencing studies is also supplied.

\section{Materials and Methods}

The data used in this review were obtained from 17 primary surveys of the $Y$-chromosome and 66 primary surveys of mtDNA. These studies were retrieved through PubMed and by searching the reference lists of the corresponding papers. Haplogroup frequencies were obtained by direct counting. Intra- and inter-populational diversity was calculated with AMOVA (Weir and Cockerham, 1984; Excoffier et al., 1992; Weir, 1996) using Arlequin 3.5.1.2 software (Excoffier and Lischer, 2010). AMOVA was also used to estimate the level of differentiation between and within 17 pre-defined language and 7 geographical catego- ries, respectively. The distribution patterns of the mtDNA haplogroup frequencies were established by generating isoline maps using IDRISI 16.0 software (IDRISI Taiga) (Eastman, 2006). Spearman's correlation coefficients were calculated with PASW Statistics 18 software. Average heterozygosity (ah) was calculated with Arlequin 3.5.1.2 software.

\section{Results and Discussion}

Table 1 gives the distribution of the $\mathrm{Q}$ and non-Qchromosomes (defined by a set of SNPs), as well as linguistic and geographical information for the samples considered. The samples were distributed from latitude $11^{\circ}$ North to $45^{\circ}$ South and longitude $46^{\circ}$ to $76^{\circ}$ West, with the individuals involved speaking 23 languages. Sample sizes varied widely from 1 to 151 individuals. Twenty-two of the studies involved less than 10 persons. Unfortunately, there is no standardization on the number of SNPs studied and in most cases only the M242 and M3 markers (which define the Asian/Native American paragroup Q* and its autochthonous Native American sublineage Q1a3a*, respec-

Table 1 - The distribution of Q and non-Q lineages and linguistic and geographical information for the samples considered.

\begin{tabular}{|c|c|c|c|c|c|}
\hline \multirow[t]{2}{*}{ Populations (n) ${ }^{1}$} & \multicolumn{2}{|c|}{ Haplogroup (\%) } & \multirow[t]{2}{*}{ Language $^{2}$} & \multirow{2}{*}{$\begin{array}{c}\text { Geographical } \\
\text { coordinates }\end{array}$} & \multirow[t]{2}{*}{ References } \\
\hline & $\begin{array}{c}\text { Q lineages / } \\
\text { Amerindian origin }\end{array}$ & $\begin{array}{l}\text { Non-Q } \\
\text { lineages }\end{array}$ & & & \\
\hline Wayuu (19) & 69 & 31 & Arawakan & $11^{\circ} \mathrm{N} ; 73^{\circ} \mathrm{W}$ & Bortolini et al. (2003) \\
\hline Kogi (17) & 100 & & Chibchan & $11^{\circ} \mathrm{N} ; 74^{\circ} \mathrm{W}$ & Rojas et al. (2010) \\
\hline Barira (12) & 100 & & Chibchan & $10^{\circ} 44^{\prime} \mathrm{N} ; 71^{\circ} 23^{\prime} \mathrm{W}$ & Bortolini et al. (2003) \\
\hline Arsario (Wiwa) (6) & 100 & & Chibchan & $10^{\circ} 25^{\prime} \mathrm{N} ; 73^{\circ} 05^{\prime} \mathrm{W}$ & Rojas et al. (2010) \\
\hline Arhuaco (Ijka) (19) & 100 & & Chibchan & $9^{\circ} 04^{\prime} \mathrm{N} ; 73^{\circ} 59^{\prime} \mathrm{W}$ & Rojas et al. (2010) \\
\hline Warao (12) & 100 & & Warao & $9^{\circ} \mathrm{N} ; 61^{\circ} \mathrm{W}$ & Bortolini et al. (2003) \\
\hline Yukpa (12) & 100 & & Carib & $8^{\circ} 40^{\prime} \mathrm{N} ; 72^{\circ} 41^{\prime} \mathrm{W}$ & Bortolini et al. (2003) \\
\hline Zenu (52) & 79 & 21 & Spanish $^{3}$ & $8^{\circ} 30^{\prime} \mathrm{N} ; 76^{\circ} \mathrm{W}$ & Bortolini et al. (2003); Rojas et al. (2010) \\
\hline Embera (13) & 92 & 8 & Choco & $7^{\circ} \mathrm{N} ; 76^{\circ} 30^{\prime} \mathrm{W}$ & Rojas et al. (2010) \\
\hline Makiritare (25) & 68 & 32 & Carib & $5^{\circ} 33^{\prime} \mathrm{N} ; 65^{\circ} 33^{\prime} \mathrm{W}$ & Lell et al. (2002) \\
\hline Kali'na (21) & 81 & 19 & Carib & $5^{\circ} 31^{\prime} \mathrm{N} ; 53^{\circ} 47^{\prime} \mathrm{W}$ & Mazières et al. (2008) \\
\hline Waunana (29) & 100 & & Choco & $4^{\circ} 50^{\prime} \mathrm{N} ; 77^{\circ} \mathrm{W}$ & Rojas et al. (2010) \\
\hline Palikur (35) & 94 & 6 & Arawakan & $4^{\circ} \mathrm{N} ; 51^{\circ} 45^{\prime} \mathrm{W}$ & Mazières et al. (2008) \\
\hline Macushi (4) & 100 & & Carib & $4^{\circ} \mathrm{N} ; 60^{\circ} 50^{\prime} \mathrm{W}$ & Lell et al. (2002) \\
\hline Piaroa (6) & 100 & & Salivan & $3^{\circ} 57^{\prime} \mathrm{N} ; 66^{\circ} 22^{\prime} \mathrm{W}$ & Lell et al. (2002) \\
\hline Wapishana (2) & 50 & 50 & Arawakan & $3^{\circ} 07^{\prime} \mathrm{N} ; 60^{\circ} 03^{\prime} \mathrm{W}$ & Lell et al. (2002) \\
\hline Emerillon (9) & 100 & & Tupi & $3^{\circ} \mathrm{N} ; 53^{\circ} \mathrm{W}$ & Mazières et al. (2008) \\
\hline Yanomámi (39) & 38 & 62 & Yanomam & $2^{\circ} 50^{\prime} \mathrm{N} ; 54^{\circ} \mathrm{W}$ & $\begin{array}{l}\text { Rodriguez-Delfin et al. (1997); Lell et al. } \\
\text { (2002) }\end{array}$ \\
\hline Tiryió (4) & 100 & & Carib & $2^{\circ} \mathrm{N} ; 56^{\circ} \mathrm{W}$ & Bortolini et al. (2003) \\
\hline Apalaí (57) & 98 & 2 & Carib & $1^{\circ} 20^{\prime} \mathrm{N} ; 54^{\circ} 40^{\prime} \mathrm{W}$ & $\begin{array}{l}\text { Rodriguez-Delfin et al. (1997); Bortolini } \\
\text { et al. (2003) }\end{array}$ \\
\hline Wayampi (62) & 100 & & Tupi & $1^{\circ} \mathrm{N} ; 53^{\circ} \mathrm{W}$ & $\begin{array}{l}\text { Rodriguez-Delfin et al. (1997); Bortolini } \\
\text { et al. (2003); Mazières et al. (2008) }\end{array}$ \\
\hline
\end{tabular}


Table 1 (cont).

\begin{tabular}{|c|c|c|c|c|c|}
\hline \multirow[t]{2}{*}{ Populations $(\mathrm{n})^{1}$} & \multicolumn{2}{|c|}{ Haplogroup (\%) } & \multirow[t]{2}{*}{ Language $^{2}$} & \multirow{2}{*}{$\begin{array}{l}\text { Geographical } \\
\text { coordinates }\end{array}$} & \multirow[t]{2}{*}{ References } \\
\hline & $\begin{array}{c}\text { Q lineages / } \\
\text { Amerindian origin }\end{array}$ & $\begin{array}{l}\text { Non-Q } \\
\text { lineages }\end{array}$ & & & \\
\hline Yagua (7) & 100 & & Peba-Yaguan & $0^{\circ} 51^{\prime} \mathrm{N} ; 72^{\circ} 27^{\prime} \mathrm{W}$ & Bortolini et al. (2003) \\
\hline Ingano (108) & 80 & 20 & Quechuan & $0^{\circ} 50^{\prime} \mathrm{N} ; 77^{\circ} \mathrm{W}$ & Bortolini et al. (2003); Rojas et al. (2010) \\
\hline Wai-Wai (9) & 100 & & Carib & $0^{\circ} 40^{\prime} \mathrm{S} ; 58^{\circ} \mathrm{W}$ & Bisso-Machado et al. (2011) \\
\hline Urubu-Kaapor (16) & 100 & & Tupi & $2^{\circ}-3^{\circ} \mathrm{S} ; 46^{\circ}-47^{\circ} \mathrm{W}$ & Bortolini et al. (2003) \\
\hline Huitoto (4) & 75 & 25 & Witotoan & $2^{\circ} 14^{\prime} \mathrm{S} ; 72^{\circ} 19^{\prime} \mathrm{W}$ & Bortolini et al. (2003) \\
\hline Arara (15) & 100 & & Carib & $\begin{array}{l}3^{\circ} 30^{\prime}-4^{\circ} 20^{\prime} \mathrm{S} \\
53^{\circ} 0^{\prime}-54^{\circ} 10^{\prime} \mathrm{W}\end{array}$ & $\begin{array}{l}\text { Rodriguez-Delfin et al. (1997); Bianchi } \\
\text { et al. (1998); Bisso-Machado et al. (2011) }\end{array}$ \\
\hline Asurini (4) & 100 & & Tupi & $\begin{array}{l}3^{\circ} 35^{\prime}-4^{\circ} 12^{\prime} \mathrm{S} \\
49^{\circ} 40^{\prime}-52^{\circ} 26^{\prime} \mathrm{W}\end{array}$ & Bortolini et al. (2003) \\
\hline Ticuna (59) & 93 & 7 & Ticuna & $4^{\circ} \mathrm{S} ; 69^{\circ} 58^{\prime} \mathrm{W}$ & Bortolini et al. (2003); Rojas et al. (2010) \\
\hline Parakanã (20) & 100 & & Tupi & $5^{\circ} 22^{\prime} \mathrm{S} ; 51^{\circ} 17^{\prime} \mathrm{W}$ & Bortolini et al. (2003) \\
\hline Xikrin (14) & 100 & & Macro-Ge & $5^{\circ} 55^{\prime} \mathrm{S} ; 51^{\circ} \mathrm{W}$ & $\begin{array}{l}\text { Bortolini et al. (2003); Bisso-Machado } \\
\text { et al. (2011) }\end{array}$ \\
\hline Suruí (24) & 96 & 4 & Tupi & $\begin{array}{l}5^{\circ} 58^{\prime}-10^{\circ} 50^{\prime} \mathrm{S} \\
48^{\circ} 39^{\prime}-61^{\circ} 10^{\prime} \mathrm{W}\end{array}$ & $\begin{array}{l}\text { Underhill et al. (1996); Bisso-Machado } \\
\text { et al. (2011) }\end{array}$ \\
\hline Araweté (4) & 100 & & Tupi & $5^{\circ} 9^{\prime} \mathrm{S} ; 52^{\circ} 22^{\prime} \mathrm{W}$ & Bisso-Machado et al. (2011) \\
\hline Munduruku (1) & 100 & & Tupi & $6^{\circ} 23^{\prime} \mathrm{S} ; 59^{\circ} 9^{\prime} \mathrm{W}$ & Bisso-Machado et al. (2011) \\
\hline Jamamadi (3) & 100 & & Arauan & $7^{\circ} 15^{\prime} \mathrm{S} ; 66^{\circ} 41^{\prime} \mathrm{W}$ & Bisso-Machado et al. (2011) \\
\hline Gorotire (19) & 100 & & Macro-Ge & $7^{\circ} 44^{\prime} \mathrm{S} ; 51^{\circ} 10^{\prime} \mathrm{W}$ & $\begin{array}{l}\text { Bortolini et al. (2003); Bisso-Machado } \\
\text { et al. (2011) }\end{array}$ \\
\hline Krahó (15) & 93 & 7 & Macro-Ge & $8^{\circ} \mathrm{S} ; 47^{\circ} 15^{\prime} \mathrm{W}$ & Lell et al. (2002); Bortolini et al. (2003) \\
\hline Kuben-Kran-Kegn (9) & 100 & & Macro-Ge & $8^{\circ} 10^{\prime} \mathrm{S} ; 52^{\circ} 8^{\prime} \mathrm{W}$ & Bisso-Machado et al. (2011) \\
\hline Tenharim (1) & 100 & & Tupi & $8^{\circ} 20^{\prime} \mathrm{S} ; 62^{\circ} \mathrm{W}$ & Bisso-Machado et al. (2011) \\
\hline Mekranoti (9) & 78 & 22 & Macro-Ge & $8^{\circ} 40^{\prime} \mathrm{S} ; 54^{\circ} \mathrm{W}$ & Bortolini et al. (2003) \\
\hline Kayapó (10) & 100 & & Macro-Ge & $9^{\circ} \mathrm{S} ; 53^{\circ} \mathrm{W}$ & Rodriguez-Delfin et al. (1997) \\
\hline Karitiana (18) & 100 & & Tupi & $9^{\circ} 30^{\prime} \mathrm{S} ; 64^{\circ} 15^{\prime} \mathrm{W}$ & $\begin{array}{l}\text { Underhill et al. (1996); Bisso-Machado } \\
\text { et al. (2011) }\end{array}$ \\
\hline Cinta-Larga (15) & 100 & & Tupi & $\begin{array}{l}9^{\circ} 50^{\prime}-12^{\circ} 30^{\prime} \mathrm{S} \\
59^{\circ} 10^{\prime}-60^{\circ} 50^{\prime} \mathrm{W}\end{array}$ & Bortolini et al. (2003) \\
\hline Gavião (7) & 100 & & Tupi & $10^{\circ} 10^{\prime} \mathrm{S} ; 61^{\circ} 8^{\prime} \mathrm{W}$ & Bisso-Machado et al. (2011) \\
\hline Karipuna (1) & & 100 & Tupi & $10^{\circ} 14^{\prime} \mathrm{S} ; 64^{\circ} 13^{\prime} \mathrm{W}$ & Bisso-Machado et al. (2011) \\
\hline Zoró (6) & 100 & & Tupi & $10^{\circ} 20^{\prime} \mathrm{S} ; 60^{\circ} 20^{\prime} \mathrm{W}$ & Bisso-Machado et al. (2011) \\
\hline Matsiguenga (28) & 91 & 9 & Arawakan & $\begin{array}{l}10^{\circ} 47^{\prime}-12^{\circ} 51^{\prime} \mathrm{S} \\
73^{\circ} 17^{\prime}-70^{\circ} 44^{\prime} \mathrm{W}\end{array}$ & Mazières et al. (2008) \\
\hline $\begin{array}{l}\text { Pacaás Novos (Wari) } \\
\text { (29) }\end{array}$ & 100 & & Chapacura-Wanham & $11^{\circ} 8^{\prime} \mathrm{S} ; 65^{\circ} \mathrm{W}$ & Bortolini et al. (2003) \\
\hline Panoa (5) & 100 & & Pano & $12^{\circ} 55^{\prime} \mathrm{S} ; 65^{\circ} 12^{\prime} \mathrm{W}$ & Lell et al. (2002) \\
\hline Xavante (15) & 100 & & Macro-Ge & $14^{\circ} \mathrm{S} ; 52^{\circ} 30^{\prime} \mathrm{W}$ & Bisso-Machado et al. (2011) \\
\hline Quechua (44) & 73 & 27 & Quechuan & $14^{\circ} 30^{\prime} \mathrm{S} ; 69^{\circ} \mathrm{W}$ & Gayà-Vidal et al. (2011) \\
\hline Aymara (59) & 97 & 3 & Aymaran & $17^{\circ} 68^{\prime} \mathrm{S} ; 6^{\circ} 16^{\prime} \mathrm{W}$ & Gayà-Vidal et al. (2011) \\
\hline Ayoreo (9) & 78 & 22 & Zamucoan & $19^{\circ} \mathrm{S} ; 60^{\circ} 30^{\prime} \mathrm{W}$ & Bailliet et al. (2009) \\
\hline Wichí (Mataco) (151) & 48 & 52 & Mataco-Guaicuru & $22^{\circ} 28^{\prime} \mathrm{S} ; 62^{\circ} 70^{\prime} \mathrm{W}$ & $\begin{array}{l}\text { Demarchi and Mitchell (2004); Bailliet } \\
\text { et al. (2009) }\end{array}$ \\
\hline Lengua (36) & 97 & 3 & Mascoian & $22^{\circ} 45^{\prime} \mathrm{S} ; 58^{\circ} 5^{\prime} \mathrm{W}$ & $\begin{array}{l}\text { Bailliet et al. (2009); Bisso-Machado et al } \\
\text { (2011) }\end{array}$ \\
\hline Chorote (9) & 89 & 21 & Mataco-Guaicuru & $22^{\circ} 90^{\prime} \mathrm{S} ; 65^{\circ} 40^{\prime} \mathrm{W}$ & Bailliet et al. (2009) \\
\hline Aché (54) & 98 & 2 & Tupi & $\begin{array}{l}23^{\circ} 30^{\prime}-24^{\circ} 10^{\prime} \mathrm{S} \\
55^{\circ} 50^{\prime}-56^{\circ} 30^{\prime} \mathrm{W}\end{array}$ & Bortolini et al. (2003) \\
\hline
\end{tabular}


Table 1 (cont).

\begin{tabular}{|c|c|c|c|c|c|}
\hline \multirow[t]{2}{*}{ Populations (n) ${ }^{1}$} & \multicolumn{2}{|c|}{ Haplogroup (\%) } & \multirow[t]{2}{*}{ Language $^{2}$} & \multirow{2}{*}{$\begin{array}{l}\text { Geographical } \\
\text { coordinates }\end{array}$} & \multirow[t]{2}{*}{ References } \\
\hline & $\begin{array}{c}\text { Q lineages / } \\
\text { Amerindian origin }\end{array}$ & $\begin{array}{l}\text { Non-Q } \\
\text { lineages }\end{array}$ & & & \\
\hline Guarani (78) & 77 & 23 & Tupi & $23^{\circ} 6^{\prime} \mathrm{S} ; 55^{\circ} 12^{\prime} \mathrm{W}$ & $\begin{array}{l}\text { Bortolini et al. (2003); Marrero et al. } \\
\text { (2007) }\end{array}$ \\
\hline Pilagá & 47 & 53 & Mataco-Guaicuru & $24^{\circ} \mathrm{S} ; 59^{\circ} \mathrm{W}$ & Demarchi and Mitchell (2004) \\
\hline Colla (63) & 35 & 65 & Quechuan $^{3}$ & $\begin{array}{l}24^{\circ} 10^{\prime}-24^{\circ} 43^{\prime} \mathrm{S} \\
65^{\circ} 17^{\prime}-65^{\circ} 52^{\prime} \mathrm{W}\end{array}$ & $\begin{array}{l}\text { Blanco-Verea et al. (2010); Toscanini } \\
\text { et al. (2011) }\end{array}$ \\
\hline Toba (89) & 88 & 12 & Mataco-Guaicuru & $26^{\circ} \mathrm{S} ; 58^{\circ} \mathrm{W}$ & $\begin{array}{l}\text { Demarchi and Mitchell (2004); Bailliet } \\
\text { et al. (2009); Toscanini et al. (2011) }\end{array}$ \\
\hline Kaingang (59) & 69 & 31 & Macro-Ge & $28^{\circ} \mathrm{S} ; 51^{\circ} 20^{\prime} \mathrm{W}$ & $\begin{array}{l}\text { Bortolini et al. (2003); Marrero et al. } \\
\text { (2007); Bisso-Machado et al. (2011) }\end{array}$ \\
\hline Diaguita (24) & 37 & 63 & Quechuan $^{4}$ & $28^{\circ} 20^{\prime} \mathrm{S} ; 67^{\circ} 43^{\prime} \mathrm{W}$ & Blanco-Verea et al. (2010) \\
\hline Mocoví (40) & 60 & 40 & Mataco-Guaicuru & $29^{\circ} 51^{\prime} \mathrm{S} ; 59^{\circ} 56^{\prime} \mathrm{W}$ & Bailliet et al. (2009) \\
\hline Pehuenche (18) & 83 & 17 & Araucanian & $37^{\circ} 43^{\prime} \mathrm{S} ; 71^{\circ} 16^{\prime} \mathrm{W}$ & Bailliet et al. (2009) \\
\hline Mapuche (105) & 36 & 64 & Araucanian & $\begin{array}{l}39^{\circ} 10^{\prime}-41^{\circ} 20^{\prime} \mathrm{S} \\
68^{\circ} 37^{\prime}-70^{\circ} 22^{\prime} \mathrm{W}\end{array}$ & $\begin{array}{l}\text { Bailliet et al. (2009); Blanco-Verea et al. } \\
\text { (2010) }\end{array}$ \\
\hline Huilliche (26) & 50 & 50 & Araucanian & $41^{\circ} 16^{\prime} \mathrm{S} ; 73^{\circ} \mathrm{W}$ & Bailliet et al. (2009) \\
\hline Tehuelche (20) & 65 & 35 & Chon & $45^{\circ} \mathrm{S} ; 71^{\circ} \mathrm{W}$ & Bailliet et al. (2009) \\
\hline
\end{tabular}

${ }^{1}$ Arranged according to latitude. ${ }^{2}$ Classification according to Lewis (2009). ${ }^{3}$ Original language is extinct. ${ }^{4}$ The Diaguita spoke originally Kakán, but this language became extinct and was substituted by Quechua.

tively; Pena et al., 1995; Bortolini et al., 2003; Seielstad et al., 2003) were investigated. This fact precludes a complete, precise view of the distribution of Q1a3a sublineages and other Q clade chromosomes in South America. For this reason, the information in Table 1 was limited to the frequencies of the $\mathrm{Q}$ and non-Q-lineages only. Note that nonQ-chromosomes (which, for the reasons given above, could not be identified in sublineages) were identified in $~ 50 \%$ of the tribal groups. For some of these populations admixture with non-Indians is known and could be the source of these non-Q chromosomes (for example, Mapuche and Guarani; Marrero et al., 2007; Bailliet et al., 2009; Blanco-Verea et al., 2010). Overall, the numbers presented in Table 1 indicate a higher presence of non- $Q$ lineages in southern populations than in those of the northern/Amazonian region, probably because of greater admixture with non-Indians in the former than in the latter. However, for some isolated groups such as the Yanomámi, it is unlikely that admixture explains the findings. In these cases other causes are more probable, such as the presence of unknown autochthonous lineages and/or known $\mathrm{Q}$ lineages whose defining markers were not tested.

Despite the great variation in the number of Y-SNPs used in these studies, Figure 1 illustrates some of the trends that were observed: The autochthonous Native American Q1a3a* is almost always the most prevalent, whereas its sublineages (Q1a3a1, Q1a3a2, Q1a3a3 and Q1a3a4) seem to have more restricted geographical distributions. The second most prevalent, Q1a3*, appears to occur equally in all regions, suggesting its presence among the first settlers of South America. The other known Q clade chromosomes
(Q1*, Q1a*, Q1a1, Q1a2, Q1a4, Q1a5, Q1a6 and Q1b) have not yet been identified in South America. Only one non-Q-chromosome $\left(\mathrm{C}^{*}\right)$ of probable native origin has been described in northwest South Amerindian populations (Figure 1; Geppert et al., 2011).

The nature of some evolutionary and demographic scenarios, mediated by men, in native American populations has also been evaluated by using $\mathrm{Y}$ microsatellite markers (Y-STRs), which have a much faster evolutionary rate than SNPs. Y-STRs allow the retrieval of population and chromosome evolutionary histories. For example, STR data have been used to estimate that the mutations that gave rise to the Q1a3a1 and Q1a3a4 sublineages occurred $7,972 \pm 2,916$ and $5,280 \pm 1,330$ years ago, probably in northwest South America and the Andean region, respectively (Bortolini et al., 2003; Jota et al., 2011).

Table 2 shows the STR allele frequencies observed in 29 South Amerindian populations, based only on Q clade chromosomes. In this compilation, we considered only studies containing information on the allele frequencies for each population individually. There was considerable variation in the number of samples tested in each study, the number of tribes, and the number of individuals per tribe. Depending on the locus considered, the number of alleles observed ranged from one to eight, with some of them appearing in only one study while others were present in almost all populations. Based on the most prevalent alleles per locus we reconstructed a probable haplotype of the ancient Native American Q-clade chromosome (ANAQC) as: 13(DYS19)-12(DYS388)-14(DYS389I)-31(DYS389II)-2 


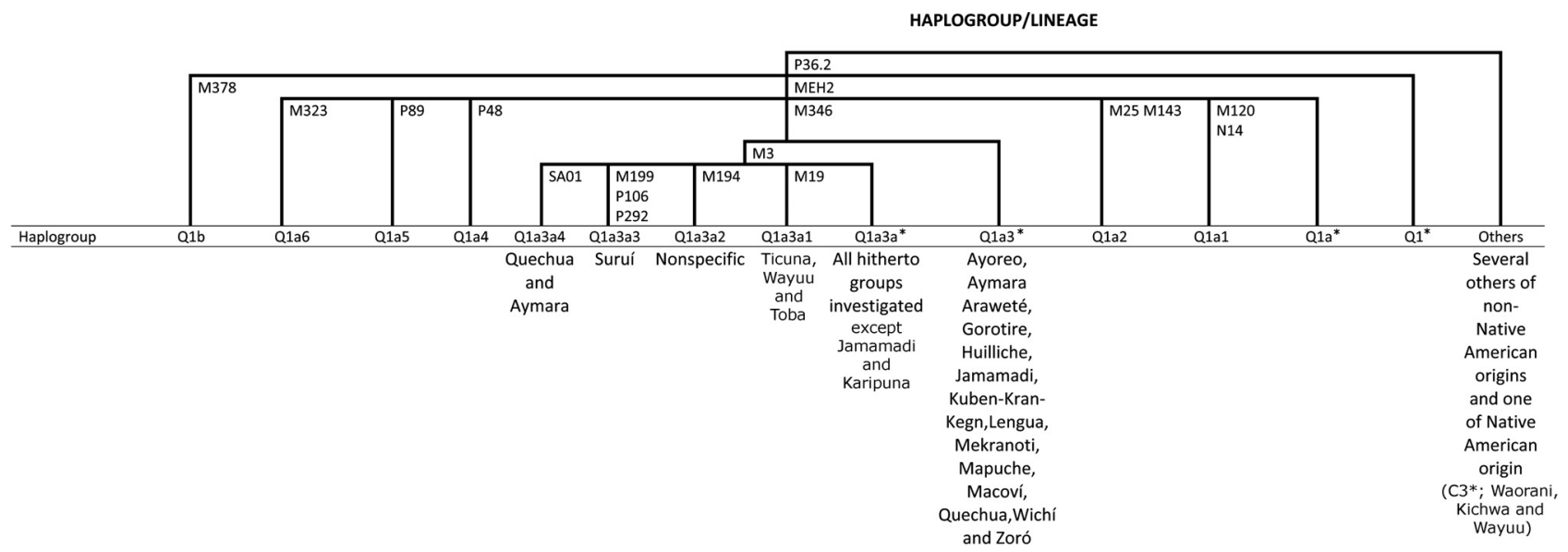

Figure 1 - Y-chromosome phylogenetic tree considering only the Q derived lineages. Note: The letters and numbers in the branches indicate the name of the loci where the mutations occurred, leading to the haplogroup classification. The data for this tree were compiled from the references in Table 1, plus Santos et al. (1995), Underhill et al. (1997, 2001), Karafet et al. (1997, 1999, 2008), Carvalho-Silva et al. (1999), Vallinoto et al. (1999), Bortolini et al. (2002), The Y-Chromosome Consortium (2002) and Geppert et al. (2011).

Table 2 (a) - Y-Q-chromosome STR studies in distinct South Amerindian samples in which allele frequencies can be assessed (Part A).

\begin{tabular}{|c|c|c|c|c|c|c|c|c|c|c|c|c|c|c|c|}
\hline \multirow[b]{2}{*}{ STR (allele) } & \multicolumn{15}{|c|}{ Ref. (n) } \\
\hline & $\begin{array}{l}\text { Aché } \\
(48)^{2}\end{array}$ & $\begin{array}{c}\text { Apalaí } \\
(9)^{1} \\
\end{array}$ & $\begin{array}{c}\text { Arara } \\
(8)^{1} \\
\end{array}$ & $\begin{array}{c}\text { Aymara } \\
(57)^{9} \\
\end{array}$ & $\begin{array}{c}\text { Ayoreo } \\
\text { (2) }\end{array}$ & $\begin{array}{c}\text { Barira } \\
(12)^{2} \\
\end{array}$ & $\begin{array}{c}\text { Diaguita } \\
(9)^{8}\end{array}$ & $\begin{array}{c}\text { Guarani } \\
(47)^{4,5}\end{array}$ & $\begin{array}{c}\text { Ingano } \\
(8)^{2}\end{array}$ & $\begin{array}{c}\text { Kaingang } \\
(17)^{5}\end{array}$ & $\begin{array}{c}\text { Kayapó } \\
(10)^{1}\end{array}$ & $\begin{array}{l}\text { Colla } \\
(22)^{6,8}\end{array}$ & $\begin{array}{l}\text { Lengua } \\
(6)^{7}\end{array}$ & $\begin{array}{l}\text { Mapuche } \\
(24)^{6,8}\end{array}$ & $\frac{\text { Mekranoti }}{(5)^{2}}$ \\
\hline DYS19 (12) & & & & 0.020 & & & & & 0.250 & & & & & & \\
\hline DYS19 (13) & 1.000 & & & 0.820 & & 0.920 & 1.000 & 0.790 & 0.620 & 0.300 & & 0.910 & 0.500 & 0.830 & 0.600 \\
\hline DYS19 (14) & & & & 0.160 & 1.000 & 0.080 & & 0.190 & 0.130 & 0.300 & & 0.090 & 0.330 & 0.040 & 0.400 \\
\hline DYS19 (15) & & & & & & & & 0.020 & & 0.350 & & & 0.170 & 0.130 & \\
\hline DYS19 (16) & & & & & & & & & & 0.050 & & & & & \\
\hline \multicolumn{16}{|l|}{ DYS19 total } \\
\hline DYS388 (12) & 1.000 & & & & & 1.000 & & & 0.750 & & & & & & 1.000 \\
\hline DYS388 (13) & & & & & & & & & 0.120 & & & & & & \\
\hline DYS388 (14) & & & & & & & & & 0.130 & & & & & & \\
\hline \multicolumn{16}{|l|}{ DYS388 (17) } \\
\hline \multicolumn{16}{|l|}{ DYS388 total } \\
\hline DYS389I (12) & & & & 0.020 & & & & 0.280 & & 0.180 & & 0.040 & 0.160 & 0.040 & \\
\hline DYS389I (13) & & & & 0.470 & 0.500 & & 0.220 & 0.020 & & 0.820 & & 0.410 & 0.500 & 0.750 & \\
\hline DYS389I (14) & & & & 0.510 & 0.500 & & 0.780 & 0.550 & & & & 0.550 & 0.170 & 0.210 & \\
\hline DYS389I (15) & & & & & & & & 0.150 & & & & & 0.170 & & \\
\hline \multicolumn{16}{|l|}{ DYS389I total } \\
\hline \multicolumn{16}{|l|}{ DYS389II (17) } \\
\hline \multicolumn{16}{|l|}{ DYS389II (18) } \\
\hline \multicolumn{16}{|l|}{ DYS389II (19) } \\
\hline DYS389II (26) & & & & & & & & & & 0.060 & & & & & \\
\hline DYS389II (27) & & & & & & & & & & & & & 0.160 & & \\
\hline DYS389II (28) & & & & 0.020 & & & & 0.020 & & 0.120 & & & & & \\
\hline DYS389II (29) & & & & 0.090 & 0.500 & & & 0.150 & & 0.290 & & 0.090 & 0.500 & 0.290 & \\
\hline DYS389II (30) & & & & 0.370 & 0.500 & & 0.440 & 0.130 & & 0.470 & & 0.180 & 0.170 & 0.420 & \\
\hline DYS389II (31) & & & & 0.450 & & & 0.560 & 0.620 & & 0.060 & & 0.500 & & 0.250 & \\
\hline DYS389II (32) & & & & 0.070 & & & & 0.080 & & & & 0.090 & 0.170 & 0.040 & \\
\hline DYS389II (33) & & & & & & & & & & & & 0.140 & & & \\
\hline \multicolumn{16}{|l|}{ DYS389II (34) } \\
\hline DYS389II total & & & & & & & & & & & & & & & \\
\hline
\end{tabular}


Table 2 (a) (cont.)

\begin{tabular}{|c|c|c|c|c|c|c|c|c|c|c|c|c|c|c|c|}
\hline \multirow[b]{2}{*}{ STR (allele) } & \multicolumn{15}{|c|}{ Ref. (n) } \\
\hline & $\begin{array}{l}\text { Aché } \\
(48)^{2}\end{array}$ & $\begin{array}{l}\text { Apalaí } \\
(9)^{1}\end{array}$ & $\begin{array}{c}\text { Arara } \\
(8)^{1}\end{array}$ & $\begin{array}{c}\text { Aymara } \\
(57)^{9}\end{array}$ & $\begin{array}{c}\text { Ayoreo } \\
(2)^{7}\end{array}$ & $\begin{array}{l}\text { Barira } \\
(12)^{2}\end{array}$ & $\begin{array}{l}\text { Diaguita } \\
(9)^{8}\end{array}$ & $\begin{array}{c}\text { Guarani } \\
(47)^{4,5}\end{array}$ & $\begin{array}{l}\text { Ingano } \\
(8)^{2}\end{array}$ & $\begin{array}{c}\text { Kaingang } \\
(17)^{5}\end{array}$ & $\begin{array}{c}\text { Kayapó } \\
(10)^{1}\end{array}$ & $\begin{array}{l}\text { Colla } \\
(22)^{6,8}\end{array}$ & $\begin{array}{l}\text { Lengua } \\
(6)^{7}\end{array}$ & $\begin{array}{c}\text { Mapuche } \\
(24)^{6,8}\end{array}$ & $\underset{(5)^{2}}{\operatorname{Mekranoti}}$ \\
\hline \multicolumn{16}{|l|}{ DYS390 (20) } \\
\hline DYS390 (21) & & 0.230 & 0.120 & 0.070 & & & & & & 0.060 & 0.100 & 0.040 & & & \\
\hline DYS390 (22) & & 0.110 & & & & & & 0.130 & & & & & & 0.040 & \\
\hline DYS390 (23) & 1.000 & 0.330 & 0.880 & 0.560 & & 0.080 & 0.330 & 0.080 & 0.250 & & 0.100 & 0.640 & 0.330 & 0.420 & 0.400 \\
\hline DYS390 (24) & & 0.330 & & 0.250 & 1.000 & 0.920 & 0.450 & 0.680 & 0.370 & 0.940 & 0.700 & 0.180 & 0.670 & 0.330 & 0.600 \\
\hline DYS390 (25) & & & & 0.120 & & & 0.220 & 0.090 & 0.250 & & 0.100 & & & 0.210 & \\
\hline DYS390 (26) & & & & & & & & 0.020 & 0.130 & & & 0.140 & & & \\
\hline \multicolumn{16}{|l|}{ DYS390 (27) } \\
\hline \multicolumn{16}{|l|}{ DYS390 total } \\
\hline DYS391 (9) & & & & 0.020 & & & & & & & & & & 0.210 & \\
\hline DYS391 (10) & 1.000 & & & 0.820 & 1.000 & 1.000 & 0.890 & 0.210 & 0.860 & & & 0.820 & 1.000 & 0.750 & 1.000 \\
\hline DYS391 (11) & & & & 0.140 & & & 0.110 & 0.790 & 0.140 & & & 0.180 & & 0.040 & \\
\hline DYS391 (12) & & & & 0.020 & & & & & & & & & & & \\
\hline \multicolumn{16}{|l|}{ DYS391 total } \\
\hline DYS392 (11) & & & & & & & & & & 0.060 & & & & & \\
\hline DYS392 (12) & & & & & & & & & & & & 0.140 & & & \\
\hline DYS392 (13) & & 1.000 & 1.000 & & & 0.920 & & 0.070 & 0.120 & 0.350 & 0.700 & 0.050 & & 0.170 & 1.000 \\
\hline DYS392 (14) & 1.000 & & & 0.470 & 0.500 & 0.080 & 0.450 & 0.720 & 0.880 & 0.530 & 0.300 & 0.360 & 0.830 & 0.710 & \\
\hline DYS392 (15) & & & & 0.040 & 0.500 & & 0.330 & 0.210 & & 0.060 & & 0.090 & 0.170 & 0.120 & \\
\hline DYS392 (16) & & & & 0.470 & & & 0.220 & & & & & 0.360 & & & \\
\hline DYS392 (17) & & & & 0.020 & & & & & & & & & & & \\
\hline \multicolumn{16}{|l|}{ DYS392 (18) } \\
\hline \multicolumn{16}{|l|}{ DYS392 total } \\
\hline DYS393 (11) & & & & & & & & 0.480 & & & & & & & \\
\hline DYS393 (12) & & 0.220 & 0.120 & & & 0.080 & & 0.090 & 0.120 & 0.060 & 0.400 & 0.090 & & & 0.400 \\
\hline DYS393 (13) & 1.000 & 0.780 & 0.880 & 0.440 & 1.000 & & 0.670 & 0.340 & 0.760 & 0.590 & 0.600 & 0.550 & 1.000 & 1.000 & 0.600 \\
\hline DYS393 (14) & & & & 0.560 & & 0.920 & 0.330 & 0.090 & 0.120 & 0.350 & & 0.360 & & & \\
\hline \multicolumn{16}{|l|}{ DYS393 (15) } \\
\hline \multicolumn{16}{|l|}{ DYS393 (16) } \\
\hline \multicolumn{16}{|l|}{ DYS393 total } \\
\hline \multicolumn{16}{|l|}{ DYS437 (8) } \\
\hline \multicolumn{16}{|l|}{ DYS437 (9) } \\
\hline DYS437 (11) & & & & & & & & & & & & & & 0.040 & \\
\hline DYS437 (14) & & & & 1.000 & & & 1.000 & 0.930 & & 0.590 & & 1.000 & & 0.920 & \\
\hline DYS437 (15) & & & & & & & & 0.070 & & 0.410 & & & & 0.040 & \\
\hline \multicolumn{16}{|l|}{ DYS437 total } \\
\hline \multicolumn{16}{|l|}{ DYS438 (9) } \\
\hline DYS438 (10) & & & & 0.050 & & & 0.220 & & & & & & & 0.040 & \\
\hline DYS438 (11) & & & & 0.930 & & & 0.670 & 0.860 & & 0.590 & & 1.000 & & 0.920 & \\
\hline DYS438 (12) & & & & 0.020 & & & 0.110 & 0.140 & & 0.410 & & & & & \\
\hline DYS438 (16) & & & & & & & & & & & & & & 0.040 & \\
\hline \multicolumn{16}{|l|}{ DYS438 total } \\
\hline DYS439 (9) & & & & & & & & & & & & 0.050 & & & \\
\hline DYS439 (10) & & & & & & & & & & 0.060 & & & & 0.130 & \\
\hline DYS439 (11) & & & & 0.160 & & & 0.220 & 0.070 & & 0.230 & & 0.050 & & 0.220 & \\
\hline DYS439 (12) & & & & 0.240 & & & 0.450 & 0.640 & & 0.590 & & 0.360 & & 0.390 & \\
\hline DYS439 (13) & & & & 0.370 & & & 0.330 & 0.290 & & 0.060 & & 0.270 & & 0.260 & \\
\hline
\end{tabular}


Table 2 (a) (cont.)

\begin{tabular}{|c|c|c|c|c|c|c|c|c|c|c|c|c|c|c|c|}
\hline \multirow[b]{2}{*}{ STR (allele) } & \multicolumn{15}{|c|}{ Ref. (n) } \\
\hline & $\begin{array}{l}\text { Aché } \\
(48)^{2}\end{array}$ & $\begin{array}{c}\text { Apalaí } \\
(9)^{1}\end{array}$ & $\begin{array}{c}\text { Arara } \\
(8)^{1}\end{array}$ & $\begin{array}{c}\text { Aymara } \\
(57)^{9}\end{array}$ & $\begin{array}{l}\text { Ayoreo } \\
\text { (2) }\end{array}$ & $\begin{array}{l}\text { Barira } \\
(12)^{2}\end{array}$ & $\begin{array}{c}\text { Diaguita } \\
(9)^{8}\end{array}$ & $\begin{array}{l}\text { Guarani } \\
(47)^{4,5} \\
\end{array}$ & $\begin{array}{c}\text { Ingano } \\
(8)^{2}\end{array}$ & $\begin{array}{c}\text { Kaingang } \\
(17)^{5}\end{array}$ & $\begin{array}{c}\text { Kayapó } \\
(10)^{1}\end{array}$ & $\begin{array}{c}\text { Colla } \\
(22)^{6,8}\end{array}$ & $\begin{array}{c}\text { Lengua } \\
(6)^{7}\end{array}$ & $\begin{array}{l}\text { Mapuche } \\
(24)^{6,8}\end{array}$ & $\begin{array}{c}\text { Mekranoti } \\
(5)^{2}\end{array}$ \\
\hline DYS439 (14) & & & & 0.230 & & & & & & 0.060 & & 0.270 & & & \\
\hline \multicolumn{16}{|l|}{ DYS439 total } \\
\hline DYS448 (18) & & & & & & & & & & & & 0.200 & & & \\
\hline DYS448 (19) & & & & 0.110 & & & & & & & & & & & \\
\hline DYS448 (20) & & & & 0.770 & & & & & & & & 0.800 & & & \\
\hline DYS448 (21) & & & & 0.120 & & & & & & & & & & & \\
\hline \multicolumn{16}{|l|}{ DYS448 (22) } \\
\hline \multicolumn{16}{|l|}{ DYS448 total } \\
\hline DYS456 (11) & & & & 0.020 & & & & & & & & & & & \\
\hline DYS456 (13) & & & & 0.050 & & & & & & & & & & & \\
\hline DYS456 (14) & & & & 0.020 & & & & & & & & & & & \\
\hline DYS456 (15) & & & & 0.800 & & & & & & & & 0.900 & & & \\
\hline DYS456 (16) & & & & 0.090 & & & & & & & & 0.100 & & & \\
\hline DYS456 (17) & & & & 0.020 & & & & & & & & & & & \\
\hline \multicolumn{16}{|l|}{ DYS456 total } \\
\hline DYS458 (13) & & & & 0.050 & & & & & & & & 0.100 & & & \\
\hline DYS458 (15) & & & & 0.030 & & & & & & & & & & & \\
\hline DYS458 (16) & & & & 0.490 & & & & & & & & 0.700 & & & \\
\hline DYS458 (17) & & & & 0.250 & & & & & & & & 0.200 & & & \\
\hline DYS458 (18) & & & & 0.140 & & & & & & & & & & & \\
\hline DYS458 (19) & & & & 0.040 & & & & & & & & & & & \\
\hline \multicolumn{16}{|l|}{ DYS458 total } \\
\hline DYS635 (22) & & & & 0.820 & & & & & & & & 0.700 & & & \\
\hline DYS635 (23) & & & & 0.160 & & & & & & & & 0.300 & & & \\
\hline \multicolumn{16}{|l|}{ DYS635 (24) } \\
\hline DYS635 (26) & & & & 0.020 & & & & & & & & & & & \\
\hline DYS635 total & & & & & & & & & & & & & & & \\
\hline
\end{tabular}

${ }^{1}$ Rodriguez-Delfin et al. (1997); ${ }^{2}$ Bortolini et al. (2003); ${ }^{3}$ Demarchi and Mitchell (2004); ${ }^{4}$ Altuna et al. (2006); ${ }^{5}$ Leite et al. (2008); ${ }^{6}$ Toscanini et al. (2008); ${ }^{7}$ Bailliet et al. (2009); ${ }^{8}$ Blanco-Verea et al. (2010); ${ }^{9}$ Gayà-Vidal et al. (2011); ${ }^{10}$ Jota et al. (2011).

Table 2 (b) - Y-Q-chromosome STR studies in distinct South Amerindian samples in which allele frequencies can be assessed (Part B).

\begin{tabular}{|c|c|c|c|c|c|c|c|c|c|c|c|c|c|c|c|}
\hline \multirow[b]{2}{*}{ STR (allele) } & \multicolumn{15}{|c|}{ Ref. (n) } \\
\hline & $\begin{array}{l}\text { Mocoví } \\
(2)^{8}\end{array}$ & $\begin{array}{c}\text { Pacaás } \\
\text { Novos }(15)^{2}\end{array}$ & $\begin{array}{l}\text { Parakanã } \\
(4)^{2}\end{array}$ & $\begin{array}{l}\text { Pilagá } \\
(9)^{3}\end{array}$ & $\begin{array}{l}\text { Quechua } \\
(58)^{10,11}\end{array}$ & $\begin{array}{l}\text { Ticuna } \\
(36)^{2}\end{array}$ & $\begin{array}{l}\text { Toba } \\
(70)^{3,7}\end{array}$ & $\begin{array}{l}\text { Warao } \\
(12)^{2}\end{array}$ & $\begin{array}{l}\text { Wayampi } \\
(10)^{1}\end{array}$ & $\begin{array}{l}\text { Wayuu } \\
(14)^{2}\end{array}$ & $\begin{array}{l}\text { Wichí } \\
(27)^{3}\end{array}$ & $\begin{array}{l}\text { Yanoma- } \\
\text { ma }(9)^{1}\end{array}$ & $\begin{array}{l}\text { Yukpa } \\
(12)^{2}\end{array}$ & $\begin{array}{l}\text { Zenu } \\
(28)^{2}\end{array}$ & $\begin{array}{l}\text { Total } \\
(590)\end{array}$ \\
\hline DYS19 (12) & & & & & & & 0.030 & & & & 0.030 & & & & 0.010 \\
\hline DYS19 (13) & 0.500 & & & 0.790 & 0.950 & 0.850 & 0.870 & 1.000 & & 0.790 & 0.640 & & 0.550 & 0.650 & 0.890 \\
\hline DYS19 (14) & 0.500 & 1.000 & & 0.210 & 0.030 & 0.090 & 0.090 & & & 0.140 & 0.230 & & 0.450 & 0.270 & 0.050 \\
\hline DYS19 (15) & & & & & 0.020 & 0.060 & 0.010 & & & 0.070 & 0.100 & & & 0.080 & 0.040 \\
\hline DYS19 (16) & & & & & & & & & & & & & & & 0.010 \\
\hline DYS19 total & & & & & & & & & & & & & & & 474 \\
\hline DYS388 (12) & & 0.860 & 1.000 & & & 0.780 & & 0.750 & & 0.570 & & & 0.500 & 0.500 & 0.780 \\
\hline DYS388 (13) & & 0.140 & & & & 0.220 & & 0.250 & & 0.430 & & & 0.500 & 0.430 & 0.200 \\
\hline DYS388 (14) & & & & & & & & & & & & & & & 0.010 \\
\hline DYS388 (17) & & & & & & & & & & & & & & 0.070 & 0.040 \\
\hline DYS388 total & & & & & & & & & & & & & & & 189 \\
\hline DYS389I (12) & & & & & 0.090 & & & & & & & & & & 0.080 \\
\hline DYS389I (13) & 1.000 & & & & 0.240 & & 0.800 & & & & & & & & 0.440 \\
\hline
\end{tabular}


Table 2 (b) (cont.)

\begin{tabular}{|c|c|c|c|c|c|c|c|c|c|c|c|c|c|c|c|}
\hline \multirow[b]{2}{*}{ STR (allele) } & \multicolumn{15}{|c|}{ Ref. (n) } \\
\hline & $\begin{array}{l}\text { Mocoví } \\
(2)^{8}\end{array}$ & $\begin{array}{c}\text { Pacaás } \\
\text { Novos }(15)^{2}\end{array}$ & $\begin{array}{c}\text { Parakanã } \\
(4)^{2}\end{array}$ & $\begin{array}{c}\text { Pilagá } \\
(9)^{3}\end{array}$ & $\begin{array}{l}\text { Quechua } \\
(58)^{10,11}\end{array}$ & $\begin{array}{c}\text { Ticuna } \\
(36)^{2}\end{array}$ & $\begin{array}{c}\text { Toba } \\
(70)^{3,7}\end{array}$ & $\begin{array}{l}\text { Warao } \\
(12)^{2}\end{array}$ & $\begin{array}{l}\text { Wayampi } \\
(10)^{1}\end{array}$ & $\begin{array}{l}\text { Wayuu } \\
(14)^{2}\end{array}$ & $\begin{array}{l}\text { Wichí } \\
(27)^{3}\end{array}$ & $\begin{array}{l}\text { Yanoma- } \\
\text { ma }(9)^{1}\end{array}$ & $\begin{array}{l}\text { Yukpa } \\
(12)^{2}\end{array}$ & $\begin{array}{l}\text { Zenu } \\
(28)^{2}\end{array}$ & $\begin{array}{l}\text { Total } \\
(590)\end{array}$ \\
\hline DYS389I (14) & & & & & 0.670 & & 0.200 & & & & & & & & 0.450 \\
\hline DYS389I (15) & & & & & & & & & & & & & & & 0.030 \\
\hline DYS389I total & & & & & & & & & & & & & & & 288 \\
\hline DYS389II (17) & & & & & 0.270 & & & & & & & & & & 0.020 \\
\hline DYS389II (18) & & & & & 0.530 & & & & & & & & & & 0.030 \\
\hline DYS389II (19) & & & & & 0.200 & & & & & & & & & & 0.010 \\
\hline DYS389II (26) & & & & & & & & & & & & & & & 0.010 \\
\hline DYS389II (27) & & & & & & & & & & & & & & & 0.010 \\
\hline DYS389II (28) & & & & & 0.090 & & & & & & & & & & 0.030 \\
\hline DYS389II (29) & & & & & 0.070 & & & & & & & & & & 0.110 \\
\hline DYS389II (30) & & & & & 0.210 & & 0.500 & & & & & & & & 0.290 \\
\hline DYS389II (31) & 0.500 & & & & 0.540 & & 0.320 & & & & & & & & 0.390 \\
\hline DYS389II (32) & 0.500 & & & & 0.090 & & 0.160 & & & & & & & & 0.080 \\
\hline DYS389II (33) & & & & & & & & & & & & & & & 0.010 \\
\hline DYS389II (34) & & & & & & & 0.020 & & & & & & & & 0.010 \\
\hline DYS389II total & & & & & & & & & & & & & & & 288 \\
\hline DYS390 (20) & & & & & 0.020 & & & & & & & & & & 0.010 \\
\hline DYS390 (21) & & & & & 0.240 & & & & & & & & & & 0.070 \\
\hline DYS390 (22) & & & & & 0.020 & & 0.080 & & & & 0.030 & 0.780 & & & 0.070 \\
\hline DYS390 (23) & 0.500 & 0.450 & & 0.210 & 0.450 & 0.060 & 0.110 & 0.080 & 1.000 & 0.220 & 0.070 & & & 0.250 & 0.320 \\
\hline DYS390 (24) & 0.500 & 0.550 & 1.000 & 0.790 & 0.220 & 0.150 & 0.730 & 0.920 & & 0.560 & 0.740 & 0.110 & 1.000 & 0.290 & 0.400 \\
\hline DYS390 (25) & & & & & 0.050 & 0.760 & 0.080 & & & 0.220 & 0.130 & & & 0.420 & 0.110 \\
\hline DYS390 (26) & & & & & & & & & & & 0.030 & & & & 0.010 \\
\hline DYS390 (27) & & & & & & 0.030 & & & & & & 0.110 & & 0.040 & 0.010 \\
\hline DYS390 total & & & & & & & & & & & & & & & 659 \\
\hline DYS391 (9) & & & & & & & & & & 0.070 & 0.030 & & & & 0.030 \\
\hline DYS391 (10) & 1.000 & 1.000 & & 0.890 & 0.840 & 0.930 & 0.900 & 0.250 & & 0.570 & 0.870 & & 1.000 & 0.640 & 0.800 \\
\hline DYS391 (11) & & & 1.000 & 0.110 & 0.160 & 0.070 & 0.100 & 0.750 & & 0.360 & 0.100 & & & 0.360 & 0.160 \\
\hline DYS391 (12) & & & & & & & & & & & & & & & 0.010 \\
\hline DYS391 total & & & & & & & & & & & & & & & 512 \\
\hline DYS392 (11) & & & & & & & 0.030 & & & 0.570 & 0.060 & & & & 0.020 \\
\hline DYS392 (12) & & & & & & & & & 1.000 & 0.070 & & & & 0.130 & 0.030 \\
\hline DYS392 (13) & 1.000 & 0.890 & & 0.100 & & & 0.100 & 0.110 & & & 0.130 & 0.890 & 0.180 & 0.060 & 0.170 \\
\hline DYS392 (14) & & 0.110 & & 0.800 & 0.520 & 0.380 & 0.670 & 0.890 & & 0.290 & 0.420 & 0.110 & 0.460 & 0.560 & 0.510 \\
\hline DYS392 (15) & & & & 0.100 & 0.070 & 0.620 & 0.190 & & & 0.070 & 0.390 & & 0.360 & 0.250 & 0.150 \\
\hline DYS392 (16) & & & & & 0.290 & & & & & & & & & & 0.100 \\
\hline DYS392 (17) & & & & & 0.020 & & & & & & & & & & 0.010 \\
\hline DYS392 (18) & & & & & 0.100 & & 0.010 & & & & & & & & 0.010 \\
\hline DYS392 total & & & & & & & & & & & & & & & 535 \\
\hline DYS393 (11) & & & 1.000 & & & & & & & & & & & & 0.040 \\
\hline DYS393 (12) & & & & & & 0.060 & 0.010 & & & 0.100 & 0.060 & & & 0.040 & 0.040 \\
\hline DYS393 (13) & 1.000 & 0.780 & & 1.000 & 0.550 & 0.710 & 0.980 & 0.750 & & 0.800 & 0.840 & 0.890 & 0.500 & 0.200 & 0.670 \\
\hline DYS393 (14) & & 0.220 & & & 0.450 & 0.170 & 0.010 & 0.250 & 1.000 & 0.100 & 0.100 & 0.110 & 0.500 & 0.240 & 0.220 \\
\hline DYS393 (15) & & & & & & 0.030 & & & & & & & & 0.480 & 0.020 \\
\hline DYS393 (16) & & & & & & 0.030 & & & & & & & & 0.040 & 0.010 \\
\hline DYS393 total & & & & & & & & & & & & & & & 584 \\
\hline
\end{tabular}


Table 2 (b) (cont.)

\begin{tabular}{|c|c|c|c|c|c|c|c|c|c|c|c|c|c|c|c|}
\hline \multirow[b]{2}{*}{ STR (allele) } & \multicolumn{15}{|c|}{ Ref. (n) } \\
\hline & $\begin{array}{l}\text { Mocoví } \\
(2)^{8}\end{array}$ & $\begin{array}{c}\text { Pacaás } \\
\text { Novos }(15)^{2}\end{array}$ & $\begin{array}{c}\text { Parakanã } \\
(4)^{2}\end{array}$ & $\begin{array}{l}\text { Pilagá } \\
(9)^{3}\end{array}$ & $\begin{array}{l}\text { Quechua } \\
(58)^{10,11}\end{array}$ & $\begin{array}{c}\text { Ticuna } \\
(36)^{2}\end{array}$ & $\begin{array}{l}\text { Toba } \\
(70)^{3,7}\end{array}$ & $\begin{array}{l}\text { Warao } \\
(12)^{2}\end{array}$ & $\begin{array}{c}\text { Wayampi } \\
(10)^{1}\end{array}$ & $\begin{array}{c}\text { Wayuu } \\
(14)^{2}\end{array}$ & $\begin{array}{l}\text { Wichí } \\
(27)^{3}\end{array}$ & $\begin{array}{l}\text { Yanoma- } \\
\text { ma }(9)^{-}\end{array}$ & $\begin{array}{l}\text { Yukpa } \\
(12)^{2}\end{array}$ & $\begin{array}{l}\text { Zenu } \\
(28)^{2}\end{array}$ & $\begin{array}{l}\text { Total } \\
(590)\end{array}$ \\
\hline DYS437 (8) & & & & 0.420 & & & 0.360 & & & & 1.000 & & & & 0.200 \\
\hline DYS437 (9) & & & & 0.580 & & & 0.030 & & & & & & & & 0.040 \\
\hline DYS437 (11) & & & & & & & & & & & & & & & 0.010 \\
\hline DYS437 (14) & & & & & 1.000 & & 0.500 & & & & & & & & 0.700 \\
\hline DYS437 (15) & & & & & & & 0.110 & & & & & & & & 0.050 \\
\hline DYS437 total & & & & & & & & & & & & & & & 322 \\
\hline DYS438 (9) & & & & & 0.020 & & & & & & & & & & 0.010 \\
\hline DYS438 (10) & & & & & & & 0.050 & & & & 0.160 & & & & 0.050 \\
\hline DYS438 (11) & & & & 0.790 & 0.930 & & 0.850 & & & & 0.840 & & & & 0.850 \\
\hline DYS438 (12) & & & & 0.210 & 0.050 & & 0.100 & & & & & & & & 0.080 \\
\hline DYS438 (16) & & & & & & & & & & & & & & & 0.010 \\
\hline DYS438 total & & & & & & & & & & & & & & & 322 \\
\hline DYS439 (9) & & & & & & & & & & & & & & & 0.010 \\
\hline DYS439 (10) & & & & & & & & & & & & & & & 0.010 \\
\hline DYS439 (11) & & & & & 0.090 & & 0.130 & & & & 0.230 & & & & 0.140 \\
\hline DYS439 (12) & & & & 0.320 & 0.240 & & 0.500 & & & & 0.710 & & & & 0.400 \\
\hline DYS439 (13) & & & & 0.680 & 0.500 & & 0.290 & & & & 0.060 & & & & 0.330 \\
\hline DYS439 (14) & & & & & 0.170 & & 0.080 & & & & & & & & 0.110 \\
\hline DYS439 total & & & & & & & & & & & & & & & 322 \\
\hline DYS448 (18) & & & & & & & & & & & & & & & 0.010 \\
\hline DYS448 (19) & & & & & 0.140 & & 0.020 & & & & & & & & 0.090 \\
\hline DYS448 (20) & & & & & 0.550 & & 0.930 & & & & & & & & 0.740 \\
\hline DYS448 (21) & & & & & 0.240 & & 0.050 & & & & & & & & 0.140 \\
\hline DYS448 (22) & & & & & 0.070 & & & & & & & & & & 0.020 \\
\hline DYS448 total & & & & & & & & & & & & & & & 169 \\
\hline DYS456 (11) & & & & & & & & & & & & & & & 0.010 \\
\hline DYS456 (13) & & & & & & & & & & & & & & & 0.020 \\
\hline DYS456 (14) & & & & & 0.230 & & 0.020 & & & & & & & & 0.090 \\
\hline DYS456 (15) & & & & & 0.720 & & 0.730 & & & & & & & & 0.750 \\
\hline DYS456 (16) & & & & & 0.050 & & 0.250 & & & & & & & & 0.120 \\
\hline DYS456 (17) & & & & & & & & & & & & & & & 0.010 \\
\hline DYS456 total & & & & & & & & & & & & & & & 169 \\
\hline DYS458 (13) & & & & & & & & & & & & & & & 0.020 \\
\hline DYS458 (15) & & & & & 0.030 & & 0.040 & & & & & & & & 0.040 \\
\hline DYS458 (16) & & & & & 0.360 & & 0.180 & & & & & & & & 0.380 \\
\hline DYS458 (17) & & & & & 0.520 & & 0.550 & & & & & & & & 0.410 \\
\hline DYS458 (18) & & & & & 0.090 & & 0.230 & & & & & & & & 0.140 \\
\hline DYS458 (19) & & & & & & & & & & & & & & & 0.010 \\
\hline DYS458 total & & & & & & & & & & & & & & & 169 \\
\hline DYS635 (22) & & & & & 0.950 & & 0.950 & & & & & & & & 0.890 \\
\hline DYS635 (23) & & & & & 0.020 & & 0.050 & & & & & & & & 0.090 \\
\hline DYS635 (24) & & & & & 0.030 & & & & & & & & & & 0.010 \\
\hline DYS635 (26) & & & & & & & & & & & & & & & 0.010 \\
\hline DYS635 total & & & & & & & & & & & & & & & 169 \\
\hline
\end{tabular}

${ }^{1}$ Rodriguez-Delfin et al. (1997); ${ }^{2}$ Bortolini et al. (2003); ${ }^{3}$ Demarchi and Mitchell (2004); ${ }^{4}$ Altuna et al. (2006); ${ }^{5}$ Leite et al. (2008); ${ }^{6}$ Toscanini et al. (2008); ${ }^{7}$ Bailliet et al. (2009); ${ }^{8}$ Blanco-Verea et al. (2010); ${ }^{9}$ Gayà-Vidal et al. (2011); ${ }^{10}$ Jota et al. (2011). 
4(DYS390)-10(DYS391)-14(DYS392)-13(DYS393)-14( DYS437)-11(DYS438)-12(DYS439)-20(DYS448)-15(D YS456)-16(DYS458)-22(DYS635). Using this information and additional data for these loci (except DYS388) reported in the Y Chromosome Haplotype Reference Database we found no matches in 36,448 haplotypes (245 populations). Although we found no complete identity with our estimated ANAQC, three one-step neighbor haplotypes were encountered, two in individuals with an admixed ancestry living in Latin American countries and one in a Native American individual (Kaqchiquel).

Table 3 shows the results of the molecular analysis of variance for populations structured by language or geography based on the data in Table 2 . The estimates were calculated for each STR locus because testing heterogeneity prevented haplotype identification. As expected, most of the diversity was attributable to intrapopulation variation, with one exception (DYS437) that was explained by the fixation of allele 14 in $40 \%$ of the populations, whereas only allele 8 was found in the Wichí. In contrast, significant variation among subdivisions was detected for only six loci (DYS398I, DYS391, DYS392, DYS393, DYS437 and DYS456) and in five out of these six it was attributable to geography. There was also considerable inter-population/within subdivision variability (significant in 28 of 30 evaluations), with the average percentage being $16 \%$ for geography and $21 \%$ for language.

Table 4 summarizes the information on sequencing studies of mitochondrial DNA. The mtDNA genome of representative individuals from 35 populations has been entirely sequenced, as reported in six publications (Ingman et al., 2000; Kivisild et al., 2006; Tamm et al., 2007; Fagundes et al., 2008; Perego et al., 2009, 2010). However, the analyses performed did not consider the within South Amerindian relationships and were mostly concerned with interethnic or interhaplogroup comparisons. Based on 86 complete Amerindian genomes, Fagundes et al. (2008) concluded that the prehistoric colonization of the Americas involved a single founding population, with an initial differentiation from Asia occurring in Beringia that ended around 19,000-23,000 years ago, with a moderate bottleneck. Expansion into the New World would have occurred about 18,000 years ago. An extensive $5.76 \mathrm{~kb}$ analysis by Dornelles et al. (2005) established that haplogroup X is not present in extant South American Indians.

The most extensive set of data involves the highly variable segment 1 (HVS-I) that has been studied in 92 populations and reported in 30 papers; surveys that have included the HVS-II region are much less common (10 articles) (Table 4). For HVS-I, Merriwether et al. (2000) provided an excellent example of how intrapopulation variability in the Yanomámi could be interpreted in a historical and demographical context and relating it to other Amerindian and Asian data. They studied 129 Yanomámi sequences from individuals in eight villages and compared
Table 3 - Analysis of molecular variance of the distinct alleles of the Y-Q STRs in relation to the language and geography of the populations tested.

\begin{tabular}{|c|c|c|c|}
\hline STR loci (structured by) & $\begin{array}{c}\text { Among } \\
\text { subdivisions }\end{array}$ & $\begin{array}{l}\text { Among populations } \\
\text { within subdivisions }\end{array}$ & $\begin{array}{c}\text { Within } \\
\text { populations }\end{array}$ \\
\hline DYS19 (Language) ${ }^{1}$ & 0 & $0.311 *$ & $0.689 *$ \\
\hline DYS19 (Geography) ${ }^{2}$ & 0 & $0.332 *$ & $0.668^{*}$ \\
\hline DYS388 (Language) $^{1}$ & 0.045 & $0.317^{*}$ & $0.638^{*}$ \\
\hline DYS388 (Geography) ${ }^{2}$ & 0.091 & $0.240^{*}$ & $0.669^{*}$ \\
\hline DYS389I (Language) ${ }^{1}$ & $0.227^{*}$ & 0.030 & $0.743 *$ \\
\hline DYS389I (Geography) ${ }^{2}$ & 0.116 & $0.148^{*}$ & $0.736^{*}$ \\
\hline DYS389II (Language) $^{1}$ & 0.036 & $0.077^{*}$ & $0.887^{*}$ \\
\hline DYS389II (Geography) ${ }^{2}$ & 0 & $0.125^{*}$ & $0.875^{*}$ \\
\hline DYS390 (Language) ${ }^{1}$ & 0.008 & $0.326^{*}$ & $0.666^{*}$ \\
\hline DYS390 (Geography) $)^{2}$ & 0 & $0.359^{*}$ & $0.642 *$ \\
\hline DYS391 (Language) $^{1}$ & 0 & $0.385^{*}$ & $0.615^{*}$ \\
\hline DYS391 (Geography) ${ }^{2}$ & $0.253^{*}$ & $0.131 *$ & $0.616^{*}$ \\
\hline DYS392 (Language) ${ }^{1}$ & 0.005 & $0.319^{*}$ & $0.676^{*}$ \\
\hline DYS392 (Geography) ${ }^{2}$ & $0.007 *$ & $0.262 *$ & $0.661 *$ \\
\hline DYS393 (Language) $^{1}$ & 0 & $0.331 *$ & $0.669 *$ \\
\hline DYS393 (Geography) ${ }^{2}$ & $0.177^{*}$ & $0.167 *$ & $0.656^{*}$ \\
\hline DYS437 (Language) ${ }^{1}$ & 0.289 & $0.273 *$ & $0.438 *$ \\
\hline DYS437 (Geography) ${ }^{2}$ & $0.390^{*}$ & $0.213^{*}$ & $0.397 *$ \\
\hline DYS438 (Language) ${ }^{1}$ & 0.048 & 0.025 & $0.927^{*}$ \\
\hline DYS438 (Geography) $)^{2}$ & 0.023 & $0.054 *$ & $0.923 *$ \\
\hline DYS439 (Language) ${ }^{1}$ & 0.019 & $0.054 *$ & $0.929 *$ \\
\hline DYS439 (Geography) ${ }^{2}$ & 0.055 & $0.034 *$ & $0.911^{*}$ \\
\hline DYS448 (Language) ${ }^{1}$ & 0 & $0.148^{*}$ & $0.852 *$ \\
\hline DYS448 (Geography) $)^{2}$ & 0 & $0.073 *$ & $0.927^{*}$ \\
\hline DYS456 (Language) $^{1}$ & 0 & $0.078^{*}$ & $0.922 *$ \\
\hline DYS456 (Geography) $)^{2}$ & $0.017^{*}$ & $0.044 *$ & $0.939 *$ \\
\hline DYS458 (Language) ${ }^{1}$ & 0 & $0.144 *$ & $0.856^{*}$ \\
\hline DYS458 (Geography) ${ }^{2}$ & 0.043 & $0.069^{*}$ & $0.888^{*}$ \\
\hline DYS635 (Language) $^{1}$ & 0 & $0.278^{*}$ & $0.722 *$ \\
\hline DYS635 (Geography) ${ }^{2}$ & 0 & $0.128^{*}$ & $0.872 *$ \\
\hline
\end{tabular}

${ }^{1}$ Language: Tupi: Aché, Guarani, Parakanã, Wayampi; Carib: Apalaí, Arara, Yukpa; Macro-Ge: Kaingang, Kayapó, Mekranoti; Quechua: Diaguita, Quechua, Ingano; Mataco-Guaicuru: Mocoví, Toba, Wichí, Pilagá; Isolated languages and others with only one population were included as a sixth group.

${ }^{2}$ Geography: Amazonia/Central Brazilian Plateau: Apalaí, Arara, Kayapó, Mekranoti, Pacaás Novos, Parakanã, Ticuna, Warao, Wayampi, Yanomámi; Southern Brazil: Guarani and Kaingang; Chaco: Ache, Ayoreo, Lengua, Mocoví, Pilagá, Toba, Wichí; Andes: Aymara, Barira, Diaguita, Kolla, Quechua, Wayuu, Yukpa, Zenu.

*Significant values $(p=0.05)$. Negative values were adjusted to zero.

their haplotypes with those of other Asian and New World populations, in a total of 482 unique haplotypes. Interestingly, the pairwise inter-population gene flow estimates were lower between some pairs of Yanomámi villages than between them and four other South Amerindian groups.

With regard to intrapopulation variability, as measured by $\Theta_{\mathrm{k}}$, Fuselli et al. (2003) and Corella et al. (2007) reported extensive variation for 14 and 27 Central and 
Table 4 - Mitochondrial DNA sequencing studies in South Amerindian populations.

\begin{tabular}{|c|c|c|c|c|}
\hline Population & HVS-I & HVS-II & Complete mt genome & References \\
\hline Aché & $\mathrm{X}$ & $\mathrm{X}$ & $\mathrm{X}$ & $\begin{array}{l}\text { Schmitt et al. (2004); Dornelles et al. (2005); Fagundes et al. (2008); } \\
\text { Yang et al. (2010) }\end{array}$ \\
\hline Ancash & $\mathrm{X}$ & & $\mathrm{X}$ & Lewis Jr et al. (2005); Perego et al. (2009) \\
\hline Andean & $\mathrm{X}$ & & & García-Bour et al. (2004) $)^{1}$ \\
\hline Apalaí & $\mathrm{X}$ & & & Lobato-da-Silva et al. (2001); Mazières et al. (2008) \\
\hline Arara & $\mathrm{X}$ & & $\mathrm{X}$ & $\begin{array}{l}\text { Santos et al. (1996); Lobato-da-Silva et al. (2001); Ribeiro-dos-Santos } \\
\text { et al. (2001); Silva Jr et al. }(2002,2003)^{2} \text {; Fagundes et al. (2008) }\end{array}$ \\
\hline Araweté & $\mathrm{X}$ & & & Lobato-da-Silva et al. (2001) \\
\hline Arequipa & $\mathrm{X}$ & & $\mathrm{X}$ & Fuselli et al. (2003); Perego et al. (2009) \\
\hline Arhuaco & $\mathrm{X}$ & $\mathrm{X}$ & $\mathrm{X}$ & Melton et al. (2007); Tamm et al. (2007); Yang et al. (2010) \\
\hline Arsario & $\mathrm{X}$ & & $\mathrm{X}$ & Melton et al. (2007); Tamm et al. (2007) \\
\hline Asurini & $\mathrm{X}$ & $\mathrm{X}$ & & Lobato-da-Silva et al. (2001); Dornelles et al. (2005) \\
\hline Auca & & & $X$ & Kivisild et al. (2006) \\
\hline Awa-Guajá & $\mathrm{X}$ & & & Santos et al. (1996); Lobato-da-Silva et al. (2001) \\
\hline Awa-Juriti & $\mathrm{X}$ & & & Lobato-da-Silva et al. (2001) \\
\hline Aymara & $\mathrm{X}$ & $X$ & & $\begin{array}{l}\text { Corella et al. (2007); Lewis Jr et al. (2007); Yang et al. (2010); } \\
\text { Barbieri et al. (2011) }\end{array}$ \\
\hline Ayoreo & $\mathrm{X}$ & $X$ & & Dornelles et al. $(2004,2005)$ \\
\hline Catamarca & & & $\mathrm{X}$ & Tamm et al. (2007) \\
\hline Cayapa & $\mathrm{X}$ & $\mathrm{X}$ & $\mathrm{X}$ & Rickards et al. (1999); Tamm et al. (2007) \\
\hline Chimane & $\mathrm{X}$ & & & Corella et al. (2007) \\
\hline Chilean North Coast & $\mathrm{X}$ & & & Moraga et al. $(2005)^{1}$ \\
\hline Cinta Larga & $\mathrm{X}$ & $\mathrm{X}$ & & Lobato-da-Silva et al. (2001); Dornelles et al. (2005) \\
\hline Coreguaje & & & $\mathrm{X}$ & Tamm et al. (2007) \\
\hline Coya & $\mathrm{X}$ & $\mathrm{X}$ & & Alvarez-Iglesias et al. (2007) \\
\hline Cubeo & $\mathrm{X}$ & $\mathrm{X}$ & & Torres et al. (2006) \\
\hline Curripaco & $\mathrm{X}$ & $\mathrm{X}$ & & Torres et al. (2006) \\
\hline Desano & $\mathrm{X}$ & $\mathrm{X}$ & & Torres et al. (2006) \\
\hline Diaguita & & & $\mathrm{X}$ & Perego et al. (2010) \\
\hline Embera & $X$ & $\mathrm{X}$ & $\mathrm{X}$ & Torres et al. (2006); Tamm et al. (2007) \\
\hline Emerillon & $\mathrm{X}$ & & & Mazières et al. (2008) \\
\hline Gavião & $\mathrm{X}$ & & $\mathrm{X}$ & Ward et al. (1996); Fagundes et al. (2008) \\
\hline Gorotire & $\mathrm{X}$ & $\mathrm{X}$ & & Dornelles et al. (2005) \\
\hline Guahibo & $\mathrm{X}$ & $X$ & & Vona et al. (2005); Torres et al. (2006) \\
\hline Guarani & $\mathrm{X}$ & $\mathrm{X}$ & $\mathrm{X}$ & $\begin{array}{l}\text { Ingman et al. (2000); Silva Jr et al. }(2002,2003)^{2} \text {; Dornelles et al. } \\
\text { (2005); Kivisild et al. (2006); Marrero et al. (2007); Fagundes et al. } \\
\text { (2008); Sala et al. (2010); Yang et al. (2010) }\end{array}$ \\
\hline Huilliche & $\mathrm{X}$ & $\mathrm{X}$ & & Yang et al. (2010) \\
\hline Huitoto & $\mathrm{X}$ & $\mathrm{X}$ & & Monsalve et al. (1994); Torres et al. (2006) \\
\hline Içana River Indians & $\mathrm{X}$ & $\mathrm{X}$ & & Dornelles et al. (2005) \\
\hline Ignaciano & $\mathrm{X}$ & & & Bert et al. (2004) \\
\hline Inga & $\mathrm{X}$ & $\mathrm{X}$ & & Torres et al. (2006); Yang et al. (2010) \\
\hline Jaqaru & $\mathrm{X}$ & & & Lewis Jr et al. (2007) \\
\hline Jamamadi & $\mathrm{X}$ & & & Lobato-da-Silva et al. (2001) \\
\hline Jebero & $\mathrm{X}$ & $\mathrm{X}$ & & Monsalve et al. (1994); Torres et al. (2006) \\
\hline Kaingang & $\mathrm{X}$ & $\mathrm{X}$ & & Dornelles et al. (2005); Marrero et al. (2007); Yang et al. (2010) \\
\hline Kali’na & $\mathrm{X}$ & & & Mazières et al. (2008) \\
\hline Karitiana & $\mathrm{X}$ & & & Lobato-da-Silva et al. (2001); \\
\hline
\end{tabular}


Table 4 (cont.)

\begin{tabular}{|c|c|c|c|c|}
\hline Population & HVS-I & HVS-II & Complete mt genome & References \\
\hline Katuena & $\mathrm{X}$ & & $\mathrm{X}$ & $\begin{array}{l}\text { Santos et al. (1996); Lobato-da-Silva et al. (2001); Silva Jr et al. } \\
(2002,2003)^{2} ; \text { Fagundes } \text { et al. (2008) }\end{array}$ \\
\hline Kayapó & $\mathrm{X}$ & & & Lobato-da-Silva et al. (2001); Silva Jr et al. $(2002,2003)^{2}$ \\
\hline Kawéskar & $\mathrm{X}$ & & & García-Bour et al. (2004) ${ }^{1}$ \\
\hline Kogi & $\mathrm{X}$ & $\mathrm{X}$ & $\mathrm{X}$ & Melton et al. (2007); Tamm et al. (2007); Yang et al. (2010) \\
\hline Kolla & & & $\mathrm{X}$ & Perego et al. (2010) \\
\hline Krahô & $\mathrm{X}$ & $\mathrm{X}$ & & Dornelles et al. (2005) \\
\hline Kikretun & $\mathrm{X}$ & & $\mathrm{X}$ & Santos et al. (1996); Fagundes et al. (2008) \\
\hline Kubenkokre & $\mathrm{X}$ & & $\mathrm{X}$ & Santos et al. (1996); Fagundes et al. (2008) \\
\hline Kuben-Kran-Kegn & $\mathrm{X}$ & $\mathrm{X}$ & & Dornelles et al. (2005) \\
\hline Lengua & $\mathrm{X}$ & $\mathrm{X}$ & & Dornelles et al. (2005) \\
\hline Mapuche & $\mathrm{X}$ & $\mathrm{X}$ & & Ginther et al. (1993); Moraga et al. (2000); Dornelles et al. (2005) \\
\hline Mekranoti & $\mathrm{X}$ & $\mathrm{X}$ & & Dornelles et al. (2005) \\
\hline Mocovi & & & $\mathrm{X}$ & Tamm et al. (2007) \\
\hline Movima & $\mathrm{X}$ & & & Bert et al. (2004); Melton et al. (2007) \\
\hline Munduruku & $\mathrm{X}$ & & & Lobato-da-Silva et al. (2001); \\
\hline Mura & $\mathrm{X}$ & $\mathrm{X}$ & & Dornelles et al. (2005) \\
\hline Ocaina & $\mathrm{X}$ & $\mathrm{X}$ & & Monsalve et al. (1994); Torres et al. (2006) \\
\hline Pacaás Novos & $\mathrm{X}$ & $\mathrm{X}$ & & Dornelles et al. (2005) \\
\hline Paez & $\mathrm{X}$ & $\mathrm{X}$ & & Torres et al. (2006) \\
\hline Palikur & $\mathrm{X}$ & & & Lobato-da-Silva et al. (2001); Mazières et al. (2008) \\
\hline Parakanã & $\mathrm{X}$ & $\mathrm{X}$ & & Lobato-da-Silva et al. (2001); Dornelles et al. (2005) \\
\hline Pehuenche & $\mathrm{X}$ & $\mathrm{X}$ & & $\begin{array}{l}\text { Merriwether et al. (1994, 1995); Merriwether and Ferrell (1996); } \\
\text { Moraga et al. (1997, 2000); García et al. (2006) }\end{array}$ \\
\hline Peruvian Andes & $\mathrm{X}$ & $\mathrm{X}$ & & Shinoda et al. $(2006)^{1}$; Fehren-Schmitz et al. $(2011)^{1}$ \\
\hline $\begin{array}{l}\text { Peruvian Southern } \\
\text { Coast }\end{array}$ & $\mathrm{X}$ & & & Fehren-Schmitz et al. $(2010)^{1}$ \\
\hline Piapoco & $\mathrm{X}$ & $\mathrm{X}$ & & Torres et al. (2006) \\
\hline Pilagá & $\mathrm{X}$ & & & Cabana et al. (2006) \\
\hline Poturujara & $\mathrm{X}$ & & $\mathrm{X}$ & $\begin{array}{l}\text { Santos et al. (1996); Lobato-da-Silva et al. (2001); Silva Jr et al. } \\
(2002,2003)^{2} ; \text { Fagundes et al. (2008) }\end{array}$ \\
\hline Puinave & $\mathrm{X}$ & $\mathrm{X}$ & & Torres et al. (2006) \\
\hline Puno & $\mathrm{X}$ & & & Lewis Jr et al. (2007) \\
\hline Quechua & $\mathrm{X}$ & $\mathrm{X}$ & $\mathrm{X}$ & $\begin{array}{l}\text { Monsalve et al. (1994); Silva Jr et al. (2002, 2003); Fuselli et al. } \\
\text { (2003); Dornelles et al. (2005); Kivisild et al. (2006); Corella et al. } \\
\text { (2007); Lewis Jr et al. (2007); Fagundes et al. (2008); Yang et al. } \\
\text { (2010); Barbieri et al. (2011) }\end{array}$ \\
\hline Saliva & $\mathrm{X}$ & $\mathrm{X}$ & & Torres et al. (2006) \\
\hline Salta & & & $\mathrm{X}$ & Tamm et al. (2007) \\
\hline Sateré Mawé & $\mathrm{X}$ & $\mathrm{X}$ & & Dornelles et al. (2005) \\
\hline Selknam & $\mathrm{X}$ & & & García-Bour et al. $(2004)^{1}$ \\
\hline Sicán & $\mathrm{X}$ & & & Shimada et al. (2004) ${ }^{1}$ \\
\hline Suruí & $\mathrm{X}$ & & $\mathrm{X}$ & Lobato-da-Silva et al. (2001); Fagundes et al. (2008) \\
\hline Tayacaja & $\mathrm{X}$ & & & Bert et al. (2004) \\
\hline Ticuna & $\mathrm{X}$ & $\mathrm{X}$ & & $\begin{array}{l}\text { Monsalve et al. (1994); Torres et al. (2006); Rojas et al. (2010); Yang } \\
\text { et al. (2010) }\end{array}$ \\
\hline Tiriyó & $\mathrm{X}$ & $\mathrm{X}$ & $\mathrm{X}$ & $\begin{array}{l}\text { Santos et al. (1996); Lobato-da-Silva et al. (2001); Silva Jr et al. } \\
(2002,2003)^{2} \text {; Dornelles et al. (2005); Fagundes et al. (2008) }\end{array}$ \\
\hline Toba & $\mathrm{X}$ & & & Cabana et al. (2006) \\
\hline
\end{tabular}


Table 4 (cont.)

\begin{tabular}{|c|c|c|c|c|}
\hline Population & HVS-I & HVS-II & Complete mt genome & References \\
\hline Trinitario & $\mathrm{X}$ & & & Bert et al. (2004) \\
\hline Tucuman & & & $\mathrm{X}$ & Tamm et al. (2007) \\
\hline Tupe & $X$ & & & Lewis Jr et al. (2007) \\
\hline Txukahamãe & $\mathrm{X}$ & $\mathrm{X}$ & & Dornelles et al. (2005) \\
\hline Uro & $\mathrm{X}$ & & & Barbieri et al. (2011) \\
\hline Urubu Kaapor & $\mathrm{X}$ & $\mathrm{X}$ & & Lobato-da-Silva et al. (2001); Dornelles et al. (2005) \\
\hline Vaupe & & & $\mathrm{X}$ & Tamm et al. (2007) \\
\hline Wai-wai & & & $\mathrm{X}$ & Fagundes et al. (2008) \\
\hline Wayampi & $\mathrm{X}$ & $\mathrm{X}$ & $\mathrm{X}$ & $\begin{array}{l}\text { Santos et al. (1996); Lobato-da-Silva et al. (2001); Silva Jr et al. } \\
(2002,2003)^{2} \text {; Dornelles et al. (2005); Fagundes et al. (2008); Mazières } \\
\text { et al. (2008) }\end{array}$ \\
\hline Warao & & & $\mathrm{X}$ & Ingman et al. (2000) \\
\hline Waunana & & & $\mathrm{X}$ & Tamm et al. (2007) \\
\hline Wayuu & $\mathrm{X}$ & $\mathrm{X}$ & $\mathrm{X}$ & $\begin{array}{l}\text { Torres et al. (2006); Melton et al. (2007); Tamm et al. (2007); Yang } \\
\text { et al. (2010) }\end{array}$ \\
\hline Wichí & $\mathrm{X}$ & & & Cabana et al. (2006) \\
\hline Xavante & $\mathrm{X}$ & $\mathrm{X}$ & $\mathrm{X}$ & Ward et al. (1996); Dornelles et al. (2005); Fagundes et al. (2008) \\
\hline Xikrin & $\mathrm{X}$ & $\mathrm{X}$ & & Lobato-da-Silva et al. (2001); Dornelles et al. (2005) \\
\hline Yagua & $\mathrm{X}$ & $\mathrm{X}$ & & Monsalve et al. (1994); Torres et al. (2006) \\
\hline Yámana & $\mathrm{X}$ & & & García-Bour et al. $(2004)^{1}$ \\
\hline Yanomámi & $\mathrm{X}$ & $\mathrm{X}$ & $\mathrm{X}$ & $\begin{array}{l}\text { Easton et al. (1996); Santos et al. (1996); Merriwether et al. (2000); } \\
\text { Lobato-da-Silva } \text { et al. (2001); Silva Jr et al. (2002, 2003) }{ }^{2} \text {; Williams } \\
\text { et al. (2002); Dornelles et al. (2005); Fagundes et al. (2008) }\end{array}$ \\
\hline Yungay & $\mathrm{X}$ & & & Lewis Jr et al. (2007) \\
\hline Yuracare & $\mathrm{X}$ & & & Bert et al. (2004) \\
\hline Zenu & $\mathrm{X}$ & $\mathrm{X}$ & & Torres et al. (2006) \\
\hline Zoró & $\mathrm{X}$ & & $\mathrm{X}$ & Ward et al. (1996); Fagundes et al. (2008) \\
\hline
\end{tabular}

${ }^{1}$ Ancient DNA. ${ }^{2}$ Sequencing included almost half of the genome (sites 7,148-15,976).

Southern Amerindian populations, respectively (e.g., from 0.659 for the Quechua of Peru to 0.011 for the Xavante of the Brazilian Mato Grosso). Intra- and intergroup nucleotide diversity was calculated by Melton et al. (2007) for 20 of these Amerindian groups, whereas Barbieri et al. (2011) compared the sources of variation among North, Central and South Amerindians in 51 populations; the latter authors observed $3 \%$ variation among the three sets, $21 \%$ variation among populations within the subcontinent and $76 \%$ variation within populations.

To explore the mtDNA data further we compiled the prevalences of haplogroups A-D for 109 populations, in a total of 6,697 individuals distributed between latitude $11^{\circ}$ North and $54^{\circ}$ South, and longitude $46^{\circ}$ to $78^{\circ}$ West (Table 5). Sample sizes varied widely, from only one subject tested (Jebero) up to 491 (Yanomámi). The haplogroup frequencies reported in 52 articles also varied widely. The presence of mtDNA genomes of probable non-Amerindian origin was rare in all regions and populations, in contrast to the Y-SNP data (Table 1). Asymmetrical sex-mediated admixture was common during the first centuries of South
American colonization, and involved mostly European men and Amerindian/African women. The main consequences of this historical contact was the formation of mestizos and the present-day national societies; the former are characterized by a composite genome, with the majority of Y-chromosomes being of European origin, while their mtDNA derives from Amerindian or African sources (Bortolini et al., 1999; Alves-Silva et al., 2000; Carvalho-Silva et al., 2001; Salzano and Bortolini, 2002). Asymmetrical mating could also explain the introduction of non-Amerindian Y-chromosomes into the tribes, while the autochthonous mtDNA genomes were preserved. However, the admixture dynamics are probably different from those observed in urban groups since they normally involve Amerindian women who live on reservations and men who live near the border of the reservations. In this situation, the children normally remain with their mothers. This phenomenon has been described for Guarani Indians (Marrero et al., 2007), but the data presented here indicate that it could be much more common than previously thought. 
Table 5 - Mitochondrial DNA haplogroup and linguistic and geographical information for the samples considered.

\begin{tabular}{|c|c|c|c|c|c|c|c|c|}
\hline \multirow[t]{2}{*}{ Population $(n)^{1}$} & \multicolumn{5}{|c|}{ Haplogroups (\%) } & \multirow[t]{2}{*}{ Language } & \multirow{2}{*}{$\begin{array}{l}\text { Geographical } \\
\text { coordinates }\end{array}$} & \multirow[t]{2}{*}{ References } \\
\hline & $\mathrm{A}$ & B & $\mathrm{C}$ & $\mathrm{D}$ & Others $^{2}$ & & & \\
\hline Wayuu (89) & 26 & 28 & 45 & 0 & 1 & Arawakan & $11^{\circ} \mathrm{N} ; 73^{\circ} \mathrm{W}$ & $\begin{array}{l}\text { Mesa et al. (2000); Keyeux et al. (2002); } \\
\text { Melton et al. (2007) }\end{array}$ \\
\hline Kogi (153) & 67 & 0 & 33 & 0 & 0 & Chibchan & $11^{\circ} \mathrm{N} ; 74^{\circ} \mathrm{W}$ & $\begin{array}{l}\text { Keyeux et al. (2002); Melton et al. } \\
\text { (2007); Rojas et al. (2010) }\end{array}$ \\
\hline Arsario (Wiwa) (76) & 63 & 0 & 37 & 0 & 0 & Chibchan & $10^{\circ} 25^{\prime} \mathrm{N} ; 73^{\circ} 05^{\prime} \mathrm{W}$ & $\begin{array}{l}\text { Keyeux et al. (2002); Melton et al. } \\
\text { (2007); Rojas et al. (2010) }\end{array}$ \\
\hline Chimila (35) & 88 & 0 & 3 & 6 & 3 & Chibchan & $10^{\circ} 16^{\prime} \mathrm{N} ; 74^{\circ} 4^{\prime} \mathrm{W}$ & Keyeux et al. (2002) \\
\hline Arhuaco (Ijka) (134) & 87 & 1 & 12 & 0 & 0 & Chibchan & $9^{\circ} 04^{\prime} \mathrm{N} ; 73^{\circ} 59^{\prime} \mathrm{W}$ & $\begin{array}{l}\text { Keyeux et al. (2002); Melton et al. } \\
\text { (2007); Rojas et al. (2010) }\end{array}$ \\
\hline Yukpa (88) & 0 & 100 & 0 & 0 & 0 & Carib & $8^{\circ} 40^{\prime} \mathrm{N} ; 72^{\circ} 41^{\prime} \mathrm{W}$ & Keyeux et al. (2002) \\
\hline Zenu (107) & 19 & 38 & 36 & 5 & 2 & Spanish & $8^{\circ} 30^{\prime} \mathrm{N} ; 76^{\circ} \mathrm{W}$ & $\begin{array}{l}\text { Mesa et al. (2000); Keyeux et al. (2002); } \\
\text { Torres et al. (2006) }\end{array}$ \\
\hline Embera (43) & 53 & 35 & 2 & 5 & 5 & Choco & $7^{\circ} \mathrm{N} ; 76^{\circ} 30^{\prime} \mathrm{W}$ & Mesa et al. (2000); Keyeux et al. (2002) \\
\hline Tule-Cuna (30) & 50 & 27 & 20 & 0 & 3 & Chibchan & $6^{\circ} 56^{\prime} \mathrm{N} ; 76^{\circ} 45^{\prime} \mathrm{W}$ & Keyeux et al. (2002) \\
\hline Guane-Butaregua (33) & 12 & 64 & 0 & 24 & 0 & Chibchan & $6^{\circ} 15^{\prime} \mathrm{N} ; 73^{\circ} 15^{\prime} \mathrm{W}$ & Keyeux et al. (2002) \\
\hline Cubeo (22) & 27 & 18 & 50 & 5 & 0 & Tucanoan & $5^{\circ} 9^{\prime} \mathrm{N} ; 70^{\circ} 18 \mathrm{~W}$ & Torres et al. (2006) \\
\hline Makiritare (10) & 20 & 0 & 70 & 10 & 0 & Carib & $5^{\circ} 33^{\prime} \mathrm{N} ; 65^{\circ} 33^{\prime} \mathrm{W}$ & Torroni et al. (1993) \\
\hline Kali’ na (Galibi) (29) & 7 & 41 & 38 & 7 & 7 & Carib & $5^{\circ} 31^{\prime} \mathrm{N} ; 53^{\circ} 47^{\prime} \mathrm{W}$ & Mazières et al. (2008) \\
\hline Guahibo (99) & 52 & 3 & 33 & 0 & 12 & Guahiban & $5^{\circ} \mathrm{N} ; 69^{\circ} \mathrm{W}$ & $\begin{array}{l}\text { Keyeux et al. (2002); Vona et al. (2005); } \\
\text { Torres et al. (2006) }\end{array}$ \\
\hline Waunana (161) & 21 & 49 & 16 & 14 & 0 & Choco & $4^{\circ} 50^{\prime} \mathrm{N} ; 77^{\circ} \mathrm{W}$ & $\begin{array}{l}\text { Keyeux et al. (2002); Tamm et al. (2007); } \\
\text { Rojas et al. (2010) }\end{array}$ \\
\hline Palikúr (64) & 1 & 47 & 4 & 47 & 1 & Arawakan & $4^{\circ} \mathrm{N} ; 51^{\circ} 45^{\prime} \mathrm{W}$ & $\begin{array}{l}\text { Lobato-da-Silva et al. (2001); Mazières et } \\
\text { al. (2008) }\end{array}$ \\
\hline Macushi (10) & 10 & 20 & 30 & 40 & 0 & Carib & $4^{\circ} \mathrm{N} ; 60^{\circ} 50^{\prime} \mathrm{W}$ & Torroni et al. (1993) \\
\hline Páez (51) & 59 & 12 & 27 & 2 & 0 & Páez & $3^{\circ} 9^{\prime} \mathrm{N} ; 75^{\circ} 28^{\prime} \mathrm{W}$ & Keyeux et al. (2002); Torres et al. (2006) \\
\hline Ocaina (2) & 0 & 0 & 100 & 0 & 0 & Witotoan & $3^{\circ} 58^{\prime} \mathrm{N} ; 68^{\circ} 2^{\prime} \mathrm{W}$ & Torres et al. (2006) \\
\hline Jebero (1) & 0 & 0 & 100 & 0 & 0 & Cahuapanan & $3^{\circ} 58^{\prime} \mathrm{N} ; 68^{\circ} 2^{\prime} \mathrm{W}$ & Torres et al. (2006) \\
\hline Piaroa (28) & 36 & 11 & 21 & 32 & 0 & Salivan & $3^{\circ} 57^{\prime} \mathrm{N} ; 66^{\circ} 22^{\prime} \mathrm{W}$ & $\begin{array}{l}\text { Torroni et al. (1993); Keyeux et al. } \\
\text { (2002) }\end{array}$ \\
\hline Desano (2) & 50 & 0 & 0 & 50 & 0 & Tucanoan & $3^{\circ} 24^{\prime} \mathrm{N} ; 69^{\circ} 40^{\prime} \mathrm{W}$ & Torres et al. (2006) \\
\hline Wapishana (12) & 0 & 25 & 8 & 67 & 0 & Arawakan & $3^{\circ} 07^{\prime} \mathrm{N} ; 60^{\circ} 03^{\prime} \mathrm{W}$ & Torroni et al. (1993) \\
\hline Emerillon (30) & 30 & 70 & 0 & 0 & 0 & Tupi & $3^{\circ} \mathrm{N} ; 53^{\circ} \mathrm{W}$ & Mazières et al. (2008) \\
\hline Guambiano (23) & 4 & 4 & 79 & 13 & 0 & Barbacoan & $2^{\circ} 6^{\prime} \mathrm{N} ; 76^{\circ} 23^{\prime} \mathrm{W}$ & Keyeux et al. (2002) \\
\hline Yanomámi (491) & 2 & 25 & 50 & 19 & 4 & Yanomam & $2^{\circ} 50^{\prime} \mathrm{N} ; 54^{\circ} \mathrm{W}$ & $\begin{array}{l}\text { Torroni et al. (1992, 1993); Easton et al. } \\
\text { (1996); Merriwether et al. (2000); } \\
\text { Williams et al. (2002); Silva Jr et al. } \\
\text { (2003) }\end{array}$ \\
\hline Guayabero (30) & 50 & 17 & 13 & 0 & 20 & Guahiban & $2^{\circ} 25^{\prime} \mathrm{N} ; 71^{\circ} 4^{\prime} \mathrm{W}$ & Keyeux et al. (2002) \\
\hline Curripaco (22) & 41 & 36 & 23 & 0 & 0 & Arawakan & $2^{\circ} 10^{\prime} \mathrm{N} ; 68^{\circ} 54^{\prime} \mathrm{W}$ & Keyeux et al. (2002); Torres et al. (2006) \\
\hline Tiriyó (32) & 9 & 19 & 22 & 47 & 3 & Carib & $2^{\circ} \mathrm{N} ; 56^{\circ} \mathrm{W}$ & $\begin{array}{l}\text { Lobato-da-Silva et al. (2001); Silva Jr et } \\
\text { al. (2003) }\end{array}$ \\
\hline Nukak (20) & 0 & 20 & 80 & 0 & 0 & Maku & $1^{\circ} 44^{\prime} \mathrm{N} ; 70^{\circ} 44^{\prime} \mathrm{W}$ & Keyeux et al. (2002) \\
\hline Apalaí (120) & 37 & 1 & 30 & 32 & 0 & Carib & $1^{\circ} 20^{\prime} \mathrm{N} ; 54^{\circ} 40^{\prime} \mathrm{W}$ & $\begin{array}{l}\text { Lobato-da-Silva et al. (2001); Mazières et } \\
\text { al. (2008) }\end{array}$ \\
\hline Cayapa (120) & 29 & 40 & 9 & 22 & 0 & Barbacoan & $1^{\circ} 17^{\prime} \mathrm{N} ; 78^{\circ} 50^{\prime} \mathrm{W}$ & Rickards et al. (1999) \\
\hline Wayampi (99) & 62 & 11 & 8 & 19 & 0 & Tupi & $1^{\circ} \mathrm{N} ; 53^{\circ} \mathrm{W}$ & $\begin{array}{l}\text { Santos et al. (1996); Lobato-da-Silva et } \\
\text { al. (2001); Silva Jr et al. (2003); Mazières } \\
\text { et al. (2008) }\end{array}$ \\
\hline Siona (12) & 75 & 17 & 8 & 0 & 0 & Tucanoan & $0^{\circ} 6^{\prime} \mathrm{N} ; 75^{\circ} 36^{\prime} \mathrm{W}$ & Keyeux et al. (2002) \\
\hline
\end{tabular}


Table 5 (cont.)

\begin{tabular}{|c|c|c|c|c|c|c|c|c|}
\hline \multirow[t]{2}{*}{ Population (n) ${ }^{1}$} & \multicolumn{5}{|c|}{ Haplogroups (\%) } & \multirow[t]{2}{*}{ Language } & \multirow{2}{*}{$\begin{array}{c}\text { Geographical } \\
\text { coordinates }\end{array}$} & \multirow[t]{2}{*}{ References } \\
\hline & A & $\mathrm{B}$ & $\mathrm{C}$ & $\mathrm{D}$ & Others $^{2}$ & & & \\
\hline Pasto (9) & 67 & 33 & 0 & 0 & 0 & Barbacoan & $0^{\circ} 58^{\prime} \mathrm{N} ; 77^{\circ} 44^{\prime} \mathrm{W}$ & Keyeux et al. (2002) \\
\hline Yagua (12) & 25 & 0 & 67 & 8 & 0 & Peba-Yaguan & $0^{\circ} 51^{\prime} \mathrm{N} ; 72^{\circ} 27^{\prime} \mathrm{W}$ & Torres et al. (2006) \\
\hline Ingano (111) & 18 & 38 & 42 & 0 & 2 & Quechuan & $0^{\circ} 50^{\prime} \mathrm{N} ; 77^{\circ} \mathrm{W}$ & $\begin{array}{l}\text { Mesa et al. (2000); Keyeux et al. (2002); } \\
\text { Torres et al. (2006); Rojas et al. (2010) }\end{array}$ \\
\hline Tucano (17) & 0 & 18 & 47 & 35 & 0 & Tucanoan & $0^{\circ} 42^{\prime} \mathrm{N} ; 69^{\circ} 53^{\prime} \mathrm{W}$ & Keyeux et al. (2002) \\
\hline Coreguaje (69) & 4 & 20 & 66 & 6 & 4 & Tucanoan & $0^{\circ} 38^{\prime} \mathrm{N} ; 76^{\circ} 8^{\prime} \mathrm{W}$ & Keyeux et al. (2002); Tamm et al. (2007) \\
\hline Awa-Juriti (18) & 0 & 72 & 11 & 0 & 17 & Tucanoan & $0^{\circ} 16^{\prime} \mathrm{N} ; 70^{\circ} 45^{\prime} \mathrm{W}$ & Lobato-da-Silva et al. (2001) \\
\hline Muinane (19) & 11 & 21 & 37 & 26 & 5 & Witotoan & $0^{\circ} 11^{\prime} \mathrm{N} ; 73^{\circ} 25^{\prime} \mathrm{W}$ & Keyeux et al. (2002) \\
\hline Poturujara (23) & 44 & 0 & 26 & 30 & 0 & Tupi & $0^{\circ} 18^{\prime} \mathrm{S} ; 55^{\circ} 18^{\prime} \mathrm{W}$ & $\begin{array}{l}\text { Lobato-da-Silva et al. (2001); Silva Jr et } \\
\text { al. (2003) }\end{array}$ \\
\hline Katuena (23) & 26 & 9 & 35 & 30 & 0 & Carib & $0^{\circ} 40^{\prime} \mathrm{S} ; 57^{\circ} 30^{\prime} \mathrm{W}$ & $\begin{array}{l}\text { Lobato-da-Silva et al. (2001); Silva Jr et } \\
\text { al. (2003) }\end{array}$ \\
\hline Wai-wai (26) & 15 & 15 & 43 & 27 & 0 & Carib & $0^{\circ} 40^{\prime} \mathrm{S} ; 58^{\circ} \mathrm{W}$ & Bonatto and Salzano (1997) \\
\hline Urubu Kaapor (42) & 21 & 31 & 14 & 29 & 5 & Tupi & $2^{\circ}-3^{\circ} \mathrm{S} ; 46^{\circ}-47^{\circ} \mathrm{W}$ & $\begin{array}{l}\text { Torroni et al. }(1992,1993) ; \\
\text { Lobato-da-Silva et al. }(2001) \text {; Dornelles } \\
\text { et al. }(2005)\end{array}$ \\
\hline Huitoto (35) & 23 & 3 & 25 & 46 & 3 & Witotoan & $2^{\circ} 14^{\prime} \mathrm{S} ; 72^{\circ} 19^{\prime} \mathrm{W}$ & Keyeux et al. (2002); Torres et al. (2006) \\
\hline Arara (70) & 54 & 20 & 26 & 0 & 0 & Carib & $\begin{array}{c}3^{\circ} 30^{\prime}-4^{\circ} 20^{\prime} \mathrm{S} ; 53^{\circ} \\
0^{\prime}-54^{\circ} 10^{\prime} \mathrm{W}\end{array}$ & $\begin{array}{l}\text { Lobato-da-Silva et al. (2001); } \\
\text { Ribeiro-dos-Santos et al. (2001); Silva Jr } \\
\text { et al. (2003); Bisso-Machado (2010, MSc } \\
\text { Dissertation, Universidade Federal do Rio } \\
\text { Grande do Sul, Porto Alegre, RS, Brazil.) }\end{array}$ \\
\hline Awa-Guajá (53) & 13 & 87 & 0 & 0 & 0 & Tupi & $3^{\circ} 30^{\prime} \mathrm{S} ; 46^{\circ} 40^{\prime} \mathrm{W}$ & Lobato-da-Silva et al. (2001) \\
\hline Asurini (24) & 4 & 54 & 17 & 21 & 4 & Tupi & $\begin{array}{c}3^{\circ} 35^{\prime}-4^{\circ} 12^{\prime} \mathrm{S} ; 49^{\circ} \\
40^{\prime}-52^{\circ} 26^{\prime} \mathrm{W}\end{array}$ & Lobato-da-Silva et al. (2001) \\
\hline Piapoco (39) & 18 & 3 & 15 & 5 & 59 & Arawakan & $3^{\circ} 36^{\prime} \mathrm{S} ; 70^{\circ} 23^{\prime} \mathrm{W}$ & Torres et al. (2006) \\
\hline Puinave (19) & 5 & 16 & 58 & 16 & 5 & Puinave & $3^{\circ} 36^{\prime} \mathrm{S} ; 70^{\circ} 23^{\prime} \mathrm{W}$ & Torres et al. (2006) \\
\hline Sáliba (13) & 15 & 0 & 55 & 15 & 15 & Salivan & $3^{\circ} 49^{\prime} \mathrm{S} ; 70^{\circ} 9^{\prime} \mathrm{W}$ & Torres et al. (2006) \\
\hline Ticuna (371) & 20 & 11 & 35 & 33 & 1 & Ticuna & $4^{\circ} \mathrm{S} ; 69^{\circ} 58^{\prime} \mathrm{W}$ & $\begin{array}{l}\text { Schurr et al. (1990); Mesa et al. (2000); } \\
\text { Torres et al. (2006); Mendes-Junior and } \\
\text { Simões (2009); Rojas et al. (2010) }\end{array}$ \\
\hline Parakanã (31) & 6 & 39 & 32 & 23 & 0 & Tupi & $5^{\circ} 22^{\prime} \mathrm{S} ; 51^{\circ} 17^{\prime} \mathrm{W}$ & $\begin{array}{l}\text { Lobato-da-Silva et al. (2001); } \\
\text { Bisso-Machado (2010, MSc Dissertation) }\end{array}$ \\
\hline Xikrin (33) & 30 & 64 & 3 & 3 & 0 & Macro-Ge & $5^{\circ} 55^{\prime} \mathrm{S} ; 51^{\circ} \mathrm{W}$ & $\begin{array}{l}\text { Lobato-da-Silva et al. (2001); Dornelles } \\
\text { et al. (2005); Bisso-Machado (2010, MSc } \\
\text { Dissertation) }\end{array}$ \\
\hline Suruí (44) & 7 & 4 & 0 & 89 & 0 & Tupi & $\begin{array}{c}5^{\circ} 58^{\prime}-10^{\circ} 50^{\prime} \mathrm{S} ; 48^{\circ} \\
39^{\prime}-61^{\circ} 10^{\prime} \mathrm{W}\end{array}$ & $\begin{array}{l}\text { Bonatto and Salzano (1997); Lobato-da- } \\
\text { Silva et al. (2001) }\end{array}$ \\
\hline Araweté (18) & 39 & 0 & 50 & 11 & 0 & Tupi & $5^{\circ} 9^{\prime} \mathrm{S} ; 52^{\circ} 22^{\prime} \mathrm{W}$ & Lobato-da-Silva et al. (2001) \\
\hline Munduruku (92) & 12 & 17 & 9 & 58 & 4 & Tupi & $6^{\circ} 23^{\prime} \mathrm{S} ; 59^{\circ} 9^{\prime} \mathrm{W}$ & $\begin{array}{l}\text { Torroni et al. }(1992,1993) \text {; } \\
\text { Lobato-da-Silva } \text { et al. (2001); Marrero et } \\
\text { al. (2007); Bisso-Machado (2010, MSc } \\
\text { Dissertation) }\end{array}$ \\
\hline Marubo (10) & 10 & 0 & 60 & 30 & 0 & Panoan & $6^{\circ} 47^{\prime} \mathrm{S} ; 72^{\circ} 80^{\prime} \mathrm{W}$ & Torroni et al. (1993) \\
\hline Jamamadi (23) & 0 & 0 & 96 & 4 & 0 & Arauan & $7^{\circ} 15^{\prime} \mathrm{S} ; 66^{\circ} 41^{\prime} \mathrm{W}$ & $\begin{array}{l}\text { Lobato-da-Silva et al. (2001); } \\
\text { Bisso-Machado (2010, MSc Dissertation) }\end{array}$ \\
\hline Yungay (38) & 5 & 45 & 34 & 16 & 0 & Quechuan & $7^{\circ} 26^{\prime} \mathrm{S} ; 77^{\circ} 4^{\prime} \mathrm{W}$ & Lewis Jr et al. (2007) \\
\hline Ancash (33) & 9 & 52 & 18 & 21 & 0 & Quechua & $7^{\circ} 41^{\prime} \mathrm{S} ; 77^{\circ} 6^{\prime} \mathrm{W}$ & Lewis Jr et al. (2005) \\
\hline Gorotire (11) & 28 & 18 & 18 & 36 & 0 & Macro-Ge & $7^{\circ} 44^{\prime} \mathrm{S} ; 51^{\circ} 10^{\prime} \mathrm{W}$ & Bisso-Machado (2010, MSc Dissertation) \\
\hline Krahó (14) & 29 & 57 & 14 & 0 & 0 & Macro-Ge & $8^{\circ} \mathrm{S} ; 47^{\circ} 15^{\prime} \mathrm{W}$ & Torroni et al. (1993) \\
\hline Kuben-Kran-Kegn (19) & 58 & 26 & 6 & 10 & 0 & Macro-Ge & $8^{\circ} 10^{\prime} \mathrm{S} ; 52^{\circ} 8^{\prime} \mathrm{W}$ & Bisso-Machado (2010, MSc Dissertation) \\
\hline
\end{tabular}


Table 5 (cont.)

\begin{tabular}{|c|c|c|c|c|c|c|c|c|}
\hline \multirow[t]{2}{*}{ Population (n) ${ }^{1}$} & \multicolumn{5}{|c|}{ Haplogroups (\%) } & \multirow[t]{2}{*}{ Language } & \multirow{2}{*}{$\begin{array}{l}\text { Geographical } \\
\text { coordinates }\end{array}$} & \multirow[t]{2}{*}{ References } \\
\hline & A & B & $\mathrm{C}$ & $\mathrm{D}$ & Others $^{2}$ & & & \\
\hline Mekranoti (19) & 26 & 63 & 11 & 0 & 0 & Macro-Ge & $8^{\circ} 40^{\prime} \mathrm{S} ; 54^{\circ} \mathrm{W}$ & $\begin{array}{l}\text { Dornelles et al. (2005); Bisso-Machado } \\
\text { (2010, MSc Dissertation) }\end{array}$ \\
\hline Kubenkokre (4) & 0 & 100 & 0 & 0 & 0 & Macro-Ge & $8^{\circ} 43^{\prime} \mathrm{S} ; 53^{\circ} 23^{\prime} \mathrm{W}$ & Marrero et al. (2007) \\
\hline Kayapó (13) & 46 & 54 & 0 & 0 & 0 & Macro-Ge & $9^{\circ} \mathrm{S} ; 53^{\circ} \mathrm{W}$ & Lobato-da-Silva et al. (2001) \\
\hline Karitiana (19) & 0 & 11 & 0 & 89 & 0 & Tupi & $9^{\circ} 30^{\prime} \mathrm{S} ; 64^{\circ} 15^{\prime} \mathrm{W}$ & Lobato-da-Silva et al. (2001) \\
\hline Cinta-Larga (45) & 25 & 0 & 20 & 53 & 2 & Tupi & $\begin{array}{c}9^{\circ} 50^{\prime}-12^{\circ} 30^{\prime} \mathrm{S} ; 59^{\circ} \\
10^{\prime}-60^{\circ} 50^{\prime} \mathrm{W}\end{array}$ & $\begin{array}{l}\text { Lobato-da-Silva et al. (2001); Dornelles } \\
\text { et al. (2005); Bisso-Machado (2010, MSc } \\
\text { Dissertation) }\end{array}$ \\
\hline Gavião (27) & 15 & 15 & 0 & 70 & 0 & Tupi & $10^{\circ} 10^{\prime} \mathrm{S} ; 61^{\circ} 8^{\prime} \mathrm{W}$ & Ward et al. (1996) \\
\hline Tupe (16) & 0 & 69 & 31 & 0 & 0 & Aymaran & $10^{\circ} 16^{\prime} \mathrm{S} ; 75^{\circ} 47^{\prime} \mathrm{W}$ & Lewis Jr et al. (2007) \\
\hline Txukahamãe (2) & 100 & 0 & 0 & 0 & 0 & Macro-Ge & $10^{\circ} 20^{\prime} \mathrm{S} ; 53^{\circ} 5^{\prime} \mathrm{W}$ & Dornelles et al. (2005) \\
\hline Zoró (30) & 20 & 7 & 13 & 60 & 0 & Tupi & $10^{\circ} 20^{\prime} \mathrm{S} ; 60^{\circ} 20^{\prime} \mathrm{W}$ & Ward et al. (1996) \\
\hline Matsiguenga (38) & 5 & 92 & 0 & 3 & 0 & Arawakan & $\begin{array}{l}10^{\circ} 47^{\prime}-12^{\circ} 51^{\prime} \mathrm{S} \\
73^{\circ} 17^{\prime}-70^{\circ} 44^{\prime} \mathrm{W}\end{array}$ & Mazières et al. (2008) \\
\hline Kokraimoro (2) & 50 & 50 & 0 & 0 & 0 & Macro-Ge & $10^{\circ} 49^{\prime} \mathrm{S} ; 55^{\circ} 27^{\prime} \mathrm{W}$ & Marrero et al. (2007) \\
\hline $\begin{array}{l}\text { Pacaás Novos (Wari) } \\
\text { (30) }\end{array}$ & 40 & 30 & 27 & 3 & 0 & $\begin{array}{l}\text { Chapacura-Wanh } \\
\text { am }\end{array}$ & $11^{\circ} 8^{\prime} \mathrm{S} ; 65^{\circ} \mathrm{W}$ & Bisso-Machado (2010, MSc Dissertation) \\
\hline Tayacaja (61) & 21 & 33 & 13 & 30 & 3 & Quechuan & $12^{\circ} 24^{\prime} \mathrm{S} ; 74^{\circ} 34^{\prime} \mathrm{W}$ & Fuselli et al. (2003) \\
\hline Arequipa (22) & 9 & 68 & 14 & 9 & 0 & Quechua & $13^{\circ} 13^{\prime} \mathrm{S} ; 72^{\circ} 11^{\prime} \mathrm{W}$ & Fuselli et al. (2003) \\
\hline Trinitario (35) & 14 & 40 & 37 & 3 & 6 & Arawakan & $14^{\circ} \mathrm{S} ; 65^{\circ} \mathrm{W}$ & Bert et al. (2001) \\
\hline Xavánte (25) & 16 & 84 & 0 & 0 & 0 & Macro-Ge & $14^{\circ} \mathrm{S} ; 52^{\circ} 30^{\prime} \mathrm{W}$ & Ward et al. (1996) \\
\hline Movima (22) & 9 & 9 & 64 & 18 & 0 & Movima & $14^{\circ} 26^{\prime} \mathrm{S} ; 65^{\circ} 53^{\prime} \mathrm{W}$ & Bert et al. (2001) \\
\hline Quechua (232) & 14 & 62 & 15 & 9 & 0 & Quechuan & $14^{\circ} 30^{\prime} \mathrm{S} ; 69^{\circ} \mathrm{W}$ & $\begin{array}{l}\text { Merriwether et al. (1995); Bert et al. } \\
\text { (2001); Silva Jr et al. (2003); Lewis Jr } \text { et } \\
\text { al. (2007); Corella et al. (2007); Barbieri } \\
\text { et al. (2011); Gayà-Vidal et al. (2011) }\end{array}$ \\
\hline Chimane (Moseten) (71) & 39 & 54 & 3 & 0 & 4 & Chimane & $14^{\circ} 41^{\prime} \mathrm{S} ; 66^{\circ} 50^{\prime} \mathrm{W}$ & Bert et al. (2001); Corella et al. (2007); \\
\hline Ignaciano (22) & 18 & 36 & 41 & 0 & 5 & Arawakan & $15^{\circ} 1^{\prime} \mathrm{S} ; 66^{\circ} 4^{\prime} \mathrm{W}$ & Bert et al. (2001) \\
\hline Uro (64) & 11 & 69 & 9 & 11 & 0 & Uru-Chipaya & $15^{\circ} 45^{\prime} \mathrm{S} ; 69^{\circ} 53^{\prime} \mathrm{W}$ & Barbieri et al. (2011) \\
\hline Yuracare (28) & 39 & 32 & 21 & 4 & 4 & Yuracare & $17^{\circ} \mathrm{S} ; 65^{\circ} \mathrm{W}$ & Bert et al. (2001) \\
\hline Aymara (411) & 4 & 76 & 8 & 11 & 1 & Aymaran & $17^{\circ} 68^{\prime} \mathrm{S} ; 69^{\circ} 16^{\prime} \mathrm{W}$ & $\begin{array}{l}\text { Merriwether et al. (1995); Easton et al. } \\
\text { (1996); Bert et al. (2001); Lewis Jr et al. } \\
\text { (2007); Corella et al. (2007); Barbieri et } \\
\text { al. (2011); Gayà-Vidal et al. (2011) }\end{array}$ \\
\hline Ayoreo (91) & 0 & 0 & 83 & 17 & 0 & Zamucoan & $19^{\circ} \mathrm{S} ; 60^{\circ} 30^{\prime} \mathrm{W}$ & Dornelles et al. (2004) \\
\hline Wichí (199) & 12 & 51 & 7 & 29 & 1 & Mataco-Guaicuru & $22^{\circ} 28^{\prime} \mathrm{S} ; 62^{\circ} 70^{\prime} \mathrm{W}$ & $\begin{array}{l}\text { Torroni et al. (1993); Bianchi et al. } \\
\text { (1995); Bravi et al. (1995); Demarchi et } \\
\text { al. (2001); Cabana et al. (2006) }\end{array}$ \\
\hline Chorote (34) & 15 & 44 & 23 & 18 & 0 & Mataco-Guaicuru & $22^{\circ} 90^{\prime} \mathrm{S} ; 65^{\circ} 40^{\prime} \mathrm{W}$ & Bianchi et al. (1995); Bravi et al. (1995) \\
\hline Humahuaca (46) & 11 & 68 & 17 & 4 & 0 & Spanish & $23^{\circ} 11^{\prime} \mathrm{S} ; 65^{\circ} 20^{\prime} \mathrm{W}$ & Dipierri et al. (1998) \\
\hline Aché (63) & 10 & 90 & 0 & 0 & 0 & Tupi & $\begin{array}{l}23^{\circ} 30^{\prime}-24^{\circ} 10^{\prime} \mathrm{S} \\
55^{\circ} 50^{\prime}-56^{\circ} 30^{\prime} \mathrm{W}\end{array}$ & Schmitt et al. (2004) \\
\hline Atacameño (79) & 13 & 73 & 10 & 4 & 0 & Atacama & $23^{\circ} 50^{\prime} \mathrm{S} ; 68^{\circ} \mathrm{W}$ & $\begin{array}{l}\text { Baillliet et al. (1994); Merriwether et al. } \\
\text { (1995); Merriwether and Ferrell (1996) }\end{array}$ \\
\hline Guarani (249) & 77 & 6 & 9 & 6 & 2 & Tupi & $23^{\circ} 6^{\prime} \mathrm{S} ; 55^{\circ} 12^{\prime} \mathrm{W}$ & $\begin{array}{l}\text { Silva Jr et al. (2003); Marrero et al. } \\
\text { (2007); García and Demarchi (2009) }\end{array}$ \\
\hline Pilagá (41) & 5 & 37 & 27 & 29 & 2 & Mataco-Guaicuru & $24^{\circ} \mathrm{S} ; 59^{\circ} \mathrm{W}$ & $\begin{array}{l}\text { Demarchi et al. (2001); Cabana et al. } \\
\text { (2006) }\end{array}$ \\
\hline Coya $(60)$ & 13 & 57 & 23 & 5 & 2 & Coya & $25^{\circ} 30^{\prime} \mathrm{S} ; 67^{\circ} 28^{\prime} \mathrm{W}$ & Álvarez-Iglesias et al. (2007) \\
\hline
\end{tabular}


Table 5 (cont.)

\begin{tabular}{|c|c|c|c|c|c|c|c|c|}
\hline \multirow[t]{2}{*}{ Population (n) ${ }^{1}$} & \multicolumn{5}{|c|}{ Haplogroups (\%) } & \multirow[t]{2}{*}{ Language } & \multirow{2}{*}{$\begin{array}{c}\text { Geographical } \\
\text { coordinates }\end{array}$} & \multirow[t]{2}{*}{ References } \\
\hline & $\mathrm{A}$ & B & $\mathrm{C}$ & $\mathrm{D}$ & Others $^{2}$ & & & \\
\hline Toba $(80)$ & 15 & 43 & 5 & 37 & 0 & Mataco-Guaicuru & $26^{\circ} \mathrm{S} ; 58^{\circ} \mathrm{W}$ & $\begin{array}{l}\text { Bianchi et al. (1995); Demarchi et al. } \\
\text { (2001); Goicoechea et al. (2001); Cabana } \\
\text { et al. (2006) }\end{array}$ \\
\hline Jujuy (19) & 16 & 58 & 16 & 10 & 0 & Spanish & $27^{\circ} 27^{\prime} \mathrm{S} ; 58^{\circ} 59^{\prime} \mathrm{W}$ & Dipierri et al. (1998) \\
\hline Kaingang (79) & 47 & 4 & 48 & 0 & 1 & Macro-Ge & $28^{\circ} \mathrm{S} ; 51^{\circ} 20^{\prime} \mathrm{W}$ & $\begin{array}{l}\text { Dornelles et al. (2005); Marrero et al. } \\
\text { (2007) }\end{array}$ \\
\hline Mocoví (5) & 80 & 0 & 0 & 20 & 0 & Mataco-Guaicuru & $29^{\circ} 51^{\prime} \mathrm{S} ; 59^{\circ} 56^{\prime} \mathrm{W}$ & Tamm et al. (2007) \\
\hline Pehuenche (205) & 2 & 9 & 40 & 49 & 0 & Araucanian & $37^{\circ} 43^{\prime} \mathrm{S} ; 71^{\circ} 16^{\prime} \mathrm{W}$ & $\begin{array}{l}\text { Merriwether et al. (1995); Moraga et al. } \\
(1997,2000)\end{array}$ \\
\hline Mapuche (314) & 5 & 23 & 32 & 36 & 4 & Araucanian & $\begin{array}{l}39^{\circ} 10^{\prime}-41^{\circ} 20^{\prime} \mathrm{S} ; \\
68^{\circ} 37^{\prime}-70^{\circ} 22^{\prime} \mathrm{W}\end{array}$ & $\begin{array}{l}\text { Ginther et al. (1993); Horai et al. (1993); } \\
\text { Bailliet et al. (1994); Bianchi et al. } \\
\text { (1995); Moraga et al. (2000) }\end{array}$ \\
\hline Huilliche (207) & 4 & 28 & 20 & 48 & 0 & Araucanian & $41^{\circ} 16^{\prime} \mathrm{S} ; 73^{\circ} \mathrm{W}$ & $\begin{array}{l}\text { Bailliet et al. (1994); Merriwether et al. } \\
\text { (1995); Merriwether and Ferrell (1996) }\end{array}$ \\
\hline Aónikenk $^{3,4}$ (15) & 0 & 0 & 27 & 73 & 0 & Chon & $45^{\circ} \mathrm{S} ; 71^{\circ} \mathrm{W}$ & $\begin{array}{l}\text { Lalueza (1995, PhD thesis, Universitat de } \\
\text { Barcelona, Barcelona, Spain) }\end{array}$ \\
\hline Tehuelche $^{4}(29)$ & 0 & 20 & 24 & 56 & 0 & Chon & $45^{\circ} \mathrm{S} ; 71^{\circ} \mathrm{W}$ & Moraga et al. (2000) \\
\hline Yámana $^{3}$ (Yaghan) (32) & 0 & 0 & 63 & 37 & 0 & Yámana & $47^{\circ} \mathrm{S} ; 74^{\circ} \mathrm{W}$ & $\begin{array}{l}\text { Lalueza (1995, PhD thesis); Moraga et al. } \\
(1997,2000)\end{array}$ \\
\hline $\begin{array}{l}\text { Kawéskar }{ }^{2} \text { (Alacaluf) } \\
\text { (19) }\end{array}$ & 0 & 0 & 16 & 84 & 0 & Alacalufan & $49^{\circ} \mathrm{S} ; 74^{\circ} \mathrm{W}$ & Lalueza (1995, PhD thesis) \\
\hline Selknam $^{2}$ (Ona) (16) & 0 & 0 & 56 & 38 & 6 & Chon & $54^{\circ} \mathrm{S} ; 74^{\circ} \mathrm{W}$ & $\begin{array}{l}\text { Lalueza (1995, PhD thesis); García-Bour } \\
\text { et al. (2004) }\end{array}$ \\
\hline
\end{tabular}

${ }^{1}$ Arranged according to latitude. ${ }^{2}$ Probably of non-Amerindian origin. ${ }^{3}$ Ancient DNA. ${ }^{4}$ Aónikenk and Tehuelche are the same tribe separated by time. Aónikenk refers to ancient DNA.

Table 6 summarizes the influence of geography. In the seven regions that were defined, $74 \%$ of the variation occurred within populations, $6 \%$ among geographic divisions and $20 \%$ among populations within divisions. To analyze this variability further, the isolated frequencies of haplogroups A to D were plotted as shown in Figure 2. High frequencies of haplogroup $\mathrm{C}$ were observed in specific regions along the northwestern portion of the continent, with additional high spots in southern Brazil and northern Argentina. The prevalences of haplogroups B and D showed a clear east-west separation, while for haplogroup A there were three main high prevalence nuclei in the north, center and south of the continent. Spearman's correlation coefficient between haplogroup frequencies and latitude yielded a positive value $(0.27 ; \mathrm{p}<0.01)$ for haplogroup A, with a corresponding negative one $(-0.25$; $\mathrm{p}<0.01)$ for haplogroup $\mathrm{D}$. The coefficients for haplogroups $\mathrm{B}$ and $\mathrm{C}$ were not significant.

Table 6 - Mitochondrial DNA haplogroup frequencies by geography ${ }^{1}$.

\begin{tabular}{|c|c|c|c|c|c|c|c|}
\hline \multirow[t]{2}{*}{ Geographic divisions } & \multirow[t]{2}{*}{ No. of populations } & \multirow[t]{2}{*}{ No. of individuals } & \multicolumn{5}{|c|}{ Haplogroups (\%) } \\
\hline & & & A & $\mathrm{B}$ & $\mathrm{C}$ & $\mathrm{D}$ & Other \\
\hline Amazonia & 55 & 2410 & 20 & 21 & 31 & 25 & 3 \\
\hline Central Plateau & 2 & 39 & 21 & 74 & 5 & 0 & 0 \\
\hline Southern Brazil & 2 & 328 & 70 & 6 & 18 & 4 & 2 \\
\hline Chaco & 6 & 479 & 10 & 43 & 22 & 24 & 1 \\
\hline Southern South America & 3 & 726 & 4 & 20 & 31 & 43 & 2 \\
\hline Tierra del Fuego & 5 & 111 & 0 & 5 & 39 & 55 & 1 \\
\hline Andes & 35 & 2604 & 27 & 45 & 20 & 7 & 1 \\
\hline Total & 108 & 6697 & & & & & \\
\hline
\end{tabular}

${ }^{1}$ AMOVA results: (a) Among geographic divisions: 6.2\%; (b) Among populations within geographic divisions: 19.5\%; (c) Within populations: 74.3\%. The three values are statistically significant. 


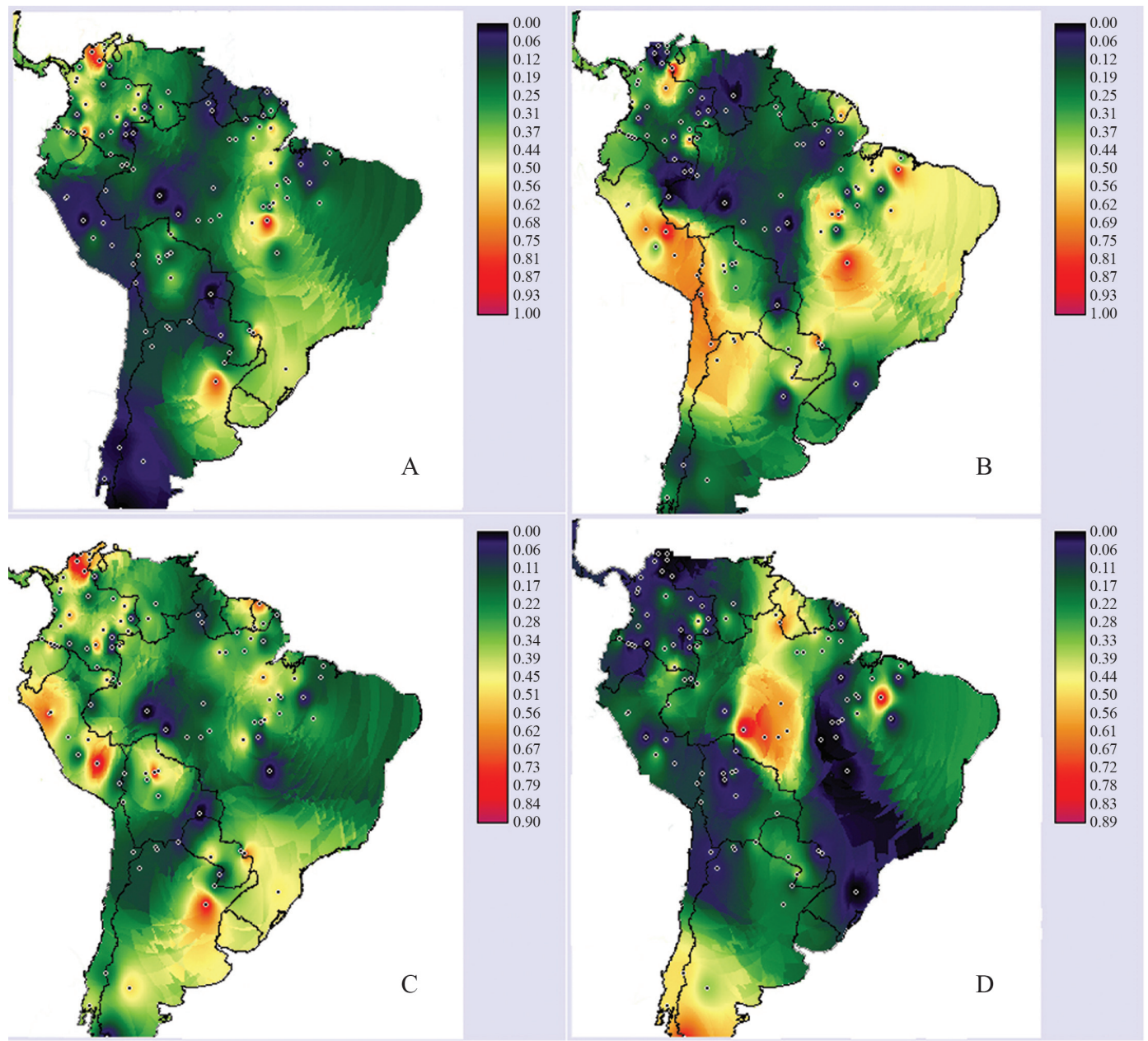

Figure 2 - Isoline map distribution showing the geographic pattern of the four (A-D) mtDNA haplogroups in South Amerindians. The dots indicate the locations of the populations sampled. As indicated in the scales given at right of each map, the colors represent the haplogroup frequencies, from dark blue (0.00) to red (1.00).

Table 7 summarizes the influence of language. Sixteen main language groups were considered, plus a composite set of "others". The AMOVA results indicated that $73 \%$ of the haplogroup prevalence variability occurred within populations, with $7 \%$ of it being attributable to languages. However, there was considerable heterogeneity $(20 \%)$ within the language categories established. Overall, the variability was similar to that obtained for geography.

Table 7 - Mitochondrial DNA haplogroup frequencies by language ${ }^{1}$.

\begin{tabular}{|c|c|c|c|c|c|c|c|}
\hline \multirow[t]{2}{*}{ Language } & \multirow[t]{2}{*}{ No. of populations } & \multirow[t]{2}{*}{ No. of individuals } & \multicolumn{5}{|c|}{ Haplogroups (\%) } \\
\hline & & & A & $\mathrm{B}$ & $\mathrm{C}$ & $\mathrm{D}$ & Other \\
\hline Tupi & 16 & 889 & 38 & 24 & 10 & 27 & 1 \\
\hline Macro-Ge & 11 & 221 & 37 & 38 & 21 & 3 & 1 \\
\hline Carib & 9 & 408 & 24 & 32 & 25 & 18 & 1 \\
\hline Chibchan & 6 & 461 & 69 & 6 & 22 & 2 & 1 \\
\hline Mataco-Guaicuru & 5 & 359 & 13 & 46 & 11 & 29 & 1 \\
\hline Arawakan & 8 & 321 & 16 & 38 & 24 & 13 & 9 \\
\hline Araucanian & 3 & 726 & 4 & 20 & 31 & 43 & 2 \\
\hline Choco & 2 & 204 & 28 & 46 & 13 & 12 & 1 \\
\hline Chon & 3 & 60 & 0 & 10 & 33 & 55 & 2 \\
\hline Tucanoan & 6 & 140 & 14 & 26 & 48 & 8 & 4 \\
\hline
\end{tabular}


Table 7 (cont.)

\begin{tabular}{|c|c|c|c|c|c|c|c|}
\hline \multirow[t]{2}{*}{ Language } & \multirow[t]{2}{*}{ No. of populations } & \multirow[t]{2}{*}{ No. of individuals } & \multicolumn{5}{|c|}{ Haplogroups (\%) } \\
\hline & & & A & $\mathrm{B}$ & $\mathrm{C}$ & $\mathrm{D}$ & Other \\
\hline Aymaran & 2 & 427 & 4 & 76 & 9 & 10 & 1 \\
\hline Barbacoan & 3 & 152 & 28 & 34 & 19 & 19 & 0 \\
\hline Guahiban & 2 & 129 & 51 & 6 & 29 & 0 & 14 \\
\hline Witotoan & 3 & 56 & 18 & 9 & 32 & 37 & 4 \\
\hline Salivan & 2 & 41 & 29 & 7 & 32 & 27 & 5 \\
\hline Quechuan & 6 & 497 & 14 & 51 & 23 & 11 & 1 \\
\hline Other & 21 & 1606 & 13 & 26 & 40 & 19 & 2 \\
\hline Total & 108 & 6697 & & & & & \\
\hline
\end{tabular}

${ }^{1}$ AMOVA results: (a) Among language groups: 6.6\%; (b) Among populations within language groups: 20.1\%; (c) Within populations: $73.3 \%$. The three values are statistically significant.

\section{Conclusion}

South Amerindians have been extensively studied with regard to the $\mathrm{Y}$-chromosome, as well as and especially so for mtDNA markers. In agreement with studies from other regions, by far most of the mtDNA variability (73\%$74 \%$ ) is intrapopulational. Geographical and linguistic factors influenced the patterns of mtDNA diversity to a similar extent, while geography was apparently more important than language in explaining the data for the $\mathrm{Y}$ chromosome Q clade-STRs. Additional factors that may have influenced these results include distinct male and female migration patterns, as well as cultural and other characteristics. The fact that most studies have generally dealt with small populations, in which genetic drift may be important, could also have influenced the results.

\section{Acknowledgments}

This work was supported by Coordenação de Aperfeiçoamento de Pessoal de Nível Superior (CAPES), Conselho Nacional de Desenvolvimento Científico e Tecnológico $(\mathrm{CNPq})$ and Fundação de Amparo à Pesquisa do Estado do Rio Grande do Sul, Programa de Apoio a Núcleos de Excelência (FAPERGS/PRONEX). We thank Sidia M. Callegari-Jacques and Luciana Tovo-Rodrigues for their help with early aspects of the statistical analyses.

\section{References}

Altuna ME, Modesti NM and Demarchi DA (2006) Y-chromosomal evidence for a founder effect in Mbyá-guaraní Amerindians from northeast Argentina. Hum Biol 78:635639.

Alvarez-Iglesias V, Jaime JC, Carracedo A and Salas A (2007) Coding region mitochondrial DNA SNPs: Targeting East Asian and Native American haplogroups. Forensic Sci Int Genet 1:44-55.

Alves-Silva J, da Silva Santos M, Guimarães PE, Ferreira AC, Bandelt HJ, Pena SD and Prado VF (2000) The ancestry of Brazilian mtDNA lineages. Am J Hum Genet 67:444-461.
Bailliet G, Rothhammer F, Carnese FR, Bravi CM and Bianchi NO (1994) Founder mitochondrial haplotypes in Amerindian populations. Am J Hum Genet 54:27-33.

Bailliet G, Ramallo V, Muzzio M, García A, Santos MR, Alfaro EL, Dipierri JE, Salceda S, Carnese FR, Bravi CM, et al. (2009) Brief communication: Restricted geographic distribution for Y-Q* paragroup in South America. Am J Phys Anthropol 140:578-582.

Barbieri C, Heggarty P, Castrì L, Luiselli D and Pettener D (2011) Mitochondrial DNA variability in the Titicaca basin: Matches and mismatches with linguistics and ethnohistory. Am J Hum Biol 23:89-99.

Bert F, Corella A, Gené M, Pérez-Pérez A and Turbón D (2001) Major mitochondrial DNA haplotype heterogeneity in highland and lowland Amerindian populations from Bolivia. Hum Biol 73:1-16.

Bert F, Corella A, Gene M, Pérez-Pérez A and Turbón D (2004) Mitochondrial DNA diversity in the Llanos de Moxos: Moxo, Movima and Yuracare Amerindian populations. Ann Hum Biol 31:9-28.

Bianchi NO, Bailliet G and Bravi CM (1995) Peopling of the Americas as inferred through the analysis of mitochondrial DNA. Braz J Genet 18:161-168.

Bianchi NO, Catanesi CI, Bailliet G, Martínez-Marignac VL, Bravi CM, Vidal-Rioja LB, Herrera RJ and López-Camelo JS (1998) Characterization of ancestral and derived Y-chromosome haplotypes of New World native populations. Am J Hum Genet 63:1862-1871.

Bisso-Machado R, Jota MS, Ramallo V, Paixão-Côrtes VR, Lacerda DR, Salzano FM, Bonatto SL, Santos FR and Bortolini MC (2011) Distribution of Y-chromosome Q lineages in Native Americans. Am J Hum Biol 23:563-566.

Blanco-Verea A, Jaime JC, Brión M and Carracedo A (2010) Y-chromosome lineages in native South American populations. Forensic Sci Int Genet 4:187-193.

Bonatto SL and Salzano FM (1997) A single and early migration for the peopling of the Americas supported by mitochondrial DNA sequence data. Proc Natl Acad Sci USA 94:18661871.

Bortolini MC, Da Silva Junior WA, De Guerra DC, Remonatto G, Mirandola R, Hutz MH, Weimer TA, Silva MC, Zago MA and Salzano FM (1999) African-derived South American populations: A history of symmetrical and asymmetrical 
matings according to sex revealed by bi- and uni-parental genetic markers. Am J Hum Biol 11:551-563.

Bortolini MC, Salzano FM, Bau CHD, Layrisse Z, Petzl-Erler ML, Tsuneto LT, Hill K, Hurtado AM, Castro-de-Guerra D, Bedoya G, et al. (2002) Y-chromosome biallelic polymorphisms and Native American population structure. Ann Hum Genet 66:255-259.

Bortolini MC, Salzano FM, Thomas MG, Stuart S, Nasanen SPK, Bau CHD, Hutz MH, Layrisse Z, Petzl-Erler ML, Tsuneto LT, et al. (2003) Y-Chromosome evidence for differing ancient demographic histories in the Americas. Am J Hum Genet 73:524-539.

Bravi CM, Cejas S, Bailliet G, Goicoechea AS, Carnese FR and Bianchi NO (1995) Haplotipos mitocondriales en Amerindios. Abstracts do XXVI Congreso Argentino de Genética, San Carlos de Bariloche, pp 152.

Cabana GS, Merriwether DA, Hunley K and Demarchi DA (2006) Is the genetic structure of Gran Chaco populations unique? Interregional perspectives on Native South American mitochondrial DNA variation. Am J Phys Anthropol 131:108119.

Carvalho-Silva DR, Santos FR, Hutz MH, Salzano FM and Pena SDJ (1999) Divergent human Y-chromosome microsatellite evolution rates. J Mol Evol 49:204-214.

Carvalho-Silva DR, Santos FR, Rocha J and Pena SD (2001) The phylogeography of Brazilian Y-chromosome lineages. Am J Hum Genet 68:281-286.

Corella A, Bert F, Pérez-Pérez A, Gené M and Turbón D (2007) Mitochondrial DNA diversity of the Amerindian populations living in the Andean Piedmont of Bolivia: Chimane, Moseten, Aymara and Quechua. Ann Hum Biol 34:34-55.

Crawford MH (1998) The Origins of Native Americans. Evidence from Anthropological Genetics. Cambridge University Press, Cambridge, 308 pp.

Demarchi DA and Mitchell RJ (2004) Genetic structure and gene flow in Gran Chaco populations of Argentina: Evidence from Y-Chromosome markers. Hum Biol 76:413-429.

Demarchi DA, Panzetta-Dutari GM, Colantonio SE and Marcellino AJ (2001) Absence of the 9-bp deletion of mitochondrial DNA in pre-Hispanic inhabitants of Argentina. Hum Biol 73:575-582.

Dipierri JE, Alfaro E, Martínez-Marignac VL, Bailliet G, Bravi CM, Cejas S and Bianchi NO (1998) Paternal directional mating in two Amerindian subpopulations located at different altitudes in northwestern Argentina. Hum Biol 70:10011010 .

Dornelles CL, Battilana J, Fagundes NJ, Freitas LB, Bonatto SL and Salzano FM (2004) Mitochondrial DNA and Alu insertions in a genetically peculiar population: The Ayoreo. Am J Hum Biol 16:479-488.

Dornelles CL, Bonatto SL, Freitas LB and Salzano FM (2005) Is haplogroup X present in extant South American Indians? Am J Phys Anthropol 127:439-448.

Eastman JR (2006) IDRISI 15.0: The Andes edition. Clark University, Worcester.

Easton RD, Merriwether DA, Crews DE and Ferrell RE (1996) mtDNA variation in the Yanomami: Evidence for additional New World founding lineages. Am J Hum Genet 59:213225.
Excoffier L and Lischer HE (2010) Arlequin suite ver 3.5: A new series of programs to perform population genetics analyses under Linux and Windows. Mol Ecol Resour 10:564-567.

Excoffier L, Smouse PE and Quattro JM (1992) Analysis of molecular variance inferred from metric distances among DNA haplotypes: Application to human mitochondrial DNA restriction data. Genetics 131:479-491.

Fagundes NJR, Kanitz R, Eckert R, Valls ACS, Bogo MR, Salzano FM, Smith DG, Silva Jr WA, Zago MA, Ribeiro-dosSantos AK, et al. (2008) Mitochondrial population genomics supports a single pre-Clovis origin with a coastal route for the peopling of the Americas. Am J Hum Genet 82:583-592.

Fehren-Schmitz L, Reindel M, Cagigao ET, Hummel S and Herrmann B (2010) Pre-Columbian population dynamics in coastal southern Peru: A diachronic investigation of mtDNA patterns in the Palpa region by ancient DNA analysis. Am J Phys Anthropol 141:208-221.

Fehren-Schmitz L, Warnberg O, Reindel M, Seidenberg V, Tomasto-Cagigao E, Isla-Cuadrado J, Hummel $\mathrm{S}$ and Herrmann B (2011) Diachronic investigations of mitochondrial and Y-chromosomal genetic markers in pre-Columbian Andean highlanders from South Peru. Ann Hum Genet 75:266-283

Fuselli S, Tarazona-Santos S, Dupanloup I, Soto A, Luiselli D and Pettener D (2003) Mitochondrial DNA diversity in South America and the genetic history of Andean Highlanders. Mol Biol Evol 20:1682-1691.

García A and Demarchi DA (2009) Incidence and distribution of Native American mtDNA haplogroups in central Argentina. Hum Biol 81:59-69.

García F, Moraga M, Vera S, Henríquez H, Llop E, Aspillaga E and Rothhammer F (2006) mtDNA microevolution in Southern Chile's archipelagos. Am J Phys Anthropol 129:473-481.

García-Bour J, Pérez-Pérez A, Álvarez S, Fernández E, LópezParra AM, Arroyo-Pardo E and Turbón D (2004) Early population differentiation in extinct aborigines from Tierra Del Fuego - Patagonia: Ancient mtDNA sequences and Y-chromosome STR characterization. Am J Phys Anthropol 123:361-370.

Gayà-Vidal M, Moral P, Saenz-Ruales N, Gerbault P, Tonasso L, Villena M, Vasquez R, Bravi CM and Dugoujon JM (2011) mtDNA and Y-chromosome diversity in Aymaras and Quechuas from Bolivia: Different stories and special genetic traits of the Andean Altiplano populations. Am J Phys Anthropol 145:215-230.

Geppert M, Baeta M, Núñez C, Martínez-Jarreta B, Zweynert S, Cruz OW, González-Andrade F, González-Solorzano J, Nagy M and Roewer L (2011) Hierarchical Y-SNP assay to study the hidden diversity and phylogenetic relationship of native populations in South America. Forensic Sci Int Genet 5:100-104.

Ginther C, Corach D, Penacino GA, Rey JA, Carnese FR, Hutz MH, Anderson A, Just J, Salzano FM and King M-C (1993) Genetic variation among the Mapuche Indians from the Patagonian region of Argentina: Mitochondrial DNA sequence variation and allele frequencies of several nuclear genes. In: Pena SDJ, Chakraborty R, Epplen JT and Jeffreys AJ (eds) DNA Fingerprinting: State of the Science. Birkhäuser Verlag, Berlin, pp 211-219. 
Goicoechea AS, Carnese FR, Dejean C, Avena SA, Weimer TA, Estalote AC, Simões ML, Palatnik M, Salamoni SP, Salzano FM, et al. (2001) New genetic data on Amerindians from the Paraguayan Chaco. Am J Hum Biol 13:660-667.

Horai S, Kondo S, Nakagawa-Hattori Y, Hayashi S, Sonoda S and Tajima K (1993) Peopling of the Americas, founded by four major lineages of mitochondrial DNA. Mol Biol Evol 10:23-47.

Hunley KL, Cabana GS, Merriwether DA and Long JC (2007) A formal test of linguistic and genetic coevolution in native Central and South America. Am J Phys Anthropol 132:622631.

Ingman M, Kaessmann H, Pääbo S and Gyllensten U (2000) Mitochondrial genome variation and the origin of modern humans. Nature 408:708-713.

Jota MS, Lacerda DR, Sandoval JR, Vieira PPR, Santos-Lopes SS, Bisso-Machado R, Paixão-Cortes VR, Revollo S, Pazy-Miño C, Fujita R, et al. (2011) A new subhaplogroup of Native American Y chromosomes from the Andes. Am J Phys Anthropol 146:553-559.

Karafet T, Segura SL, Vuturo-Brady J, Posukh O, Osipova L, Wiebe V, Romero F, Long JC, Harihara S, Jin F, et al. (1997) Y chromosome markers and trans-Bering Strait dispersals. Am J Phys Anthropol 102:301-314.

Karafet TM, Zegura SL, Posukh O, Osipova L, Bergen A, Long J, Goldman D, Klitz W, Harihara S, de Knijff P, et al. (1999) Ancestral Asian source(s) of New World Y-chromosome founder haplotypes. Am J Hum Genet 64:817-831.

Karafet TM, Mendez FL, Meilerman MB, Underhill PA, Zegura SL and Hammer MF (2008) New binary polymorphisms reshape and increase resolution of the human Y chromosomal haplogroup tree. Genome Res 18:830-838.

Keyeux G, Rodas C, Gelvez N and Carter D (2002) Possible migration routes into South America deduced from mitochondrial DNA studies in Colombian Amerindian populations. Hum Biol 74:211-233.

Kivisild T, Shen P, Wall D, Do B, Sung R, Davis K, Passarino G, Underhill PA, Scharfe C, Torroni A, et al. (2006) The role of selection in the evolution of human mitochondrial genomes. Genetics 172:373-387.

Leite FP, Callegari-Jacques SM, Carvalho BA, Kommers T, Matte CH, Raimann PE, Schwengber SP, Sortica VA, Tsuneto LT, Petzl-Erler ML, et al. (2008) Y-STR analysis in Brazilian and South Amerindian populations. Am J Hum Biol 20:359-363.

Lell JT, Sukernik RI, Starikovskaya YB, Su B, Jin L, Schurr TG, Underhill PA and Wallace DC (2002) The dual origin and Siberian affinities of Native American Y chromosomes. Am J Hum Genet 70:192-206.

Lewis Jr CM, Tito RY, Lizárraga B and Stone AC (2005) Land, language, and loci: mtDNA in Native Americans and the genetic history of Peru. Am J Phys Anthropol 127:351-360.

Lewis Jr CM, Buikstra JE and Stone AC (2007) Ancient DNA and genetic continuity in the South Central Andes. Lat Am Antiq 18:1-48.

Lobato-da-Silva DF, Ribeiro-dos-Santos AKC and Santos SEB (2001) Diversidade genética de populações humanas na Amazônia. In: Guimarães Vieira IC, Cardoso da Silva JM, Oren DC and D'Ineao MA (eds) Diversidade Humana e Cultural na Amazônia. Museu Paraense Emilio Goeldi, Belém, pp 167-193.
Marrero AR, Silva-Junior WA, Bravi CM, Hutz MH, Petzl-Erler ML, Ruiz-Linares A, Salzano FM and Bortolini MC (2007) Demographic and evolutionary trajectories of the Guarani and Kaingang natives of Brazil. Am J Phys Anthropol 132:301-310.

Mazières S, Guitard E, Crubézy E, Dugoujon JM, Bortolini MC, Bonatto SL, Hutz MH, Bois E, Tiouka F, Larrouy G, et al. (2008) Uniparental (mtDNA, Y-chromosome) polymorphisms in French Guiana and two related populations - Implications for the region's colonization. Ann Hum Genet 72:145-156.

Melton PE, Briceño I, Gómez A, Devor EJ, Bernal JE and Crawford MH (2007) Biological relationship between Central and South American Chibchan speaking populations: Evidence from mtDNA. Am J Phys Anthropol 133:753-770.

Mendes-Junior CT and Simões AL (2009) Mitochondrial DNA variability among eight Tikúna villages: Evidence for an intratribal genetic heterogeneity pattern. Am J Phys Anthropol 140:526-531.

Merriwether DA and Ferrell RE (1996) The four founding lineage hypothesis for the New World: A critical reevaluation. Mol Phylogenet Evol 5:241-246.

Merriwether DA, Rothhammer F and Ferrell RE (1994) Genetic variation in the New World: Ancient teeth, bone, and tissue as sources of DNA. Experientia 50:592-601.

Merriwether DA, Rothhammer F and Ferrell RE (1995) Distribution of the four founding lineage haplotypes in Native Americans suggests a single wave of migration for the New World. Am J Phys Anthropol 98:411-430.

Merriwether DA, Kemp BM, Crews DE and Neel JV (2000) Gene flow and genetic variation in the Yanomama as revealed by mitochondrial DNA. In: Renfrew C (ed) America Past, America Present: Genes and Languages in the Americas and Beyond. Oxbow books, Oxford, pp 89-124.

Mesa NR, Mondragón MC, Soto ID, Parra MV, Duque C, OrtízBarrientos D, García LF, Velez ID, Bravo ML, Múnera JG, et al. (2000) Autosomal, mtDNA, and Y-chromosome diversity in Amerindians: Pre- and post-Columbian patterns of gene flow in South America. Am J Hum Genet 67:12771286.

Monsalve MV, Groot de Restrepo H, Espinel A, Correal G and Devine DV (1994) Evidence of mitochondrial DNA diversity in South American aboriginals. Ann Hum Genet 58:265-273.

Moraga M, Rothhammer F and Carvallo P (1997) Mitochondrial DNA variation in aboriginal populations of southern Chile. In: Barton SA, Rothhammer F and Schull WS (eds) Patterns of Morbidity in Andean Aboriginal Populations: 8,000 Years of Evolution. Amphora Editora, Santiago, pp 32-36.

Moraga ML, Rocco P, Miquel JF, Nervi F, Llop E, Chakraborty R, Rothhammer F and Carvallo P (2000) Mitochondrial DNA polymorphisms in Chilean aboriginal populations: Implications for the peopling of the southern cone of the continent. Am J Phys Anthropol 113:19-29.

Moraga M, Santoro CM, Standen VG, Carvallo P and Rothhammer F (2005) Microevolution in prehistoric Andean populations: Chronologic mtDNA variation in the desert valleys of northern Chile. Am J Phys Anthropol 127:170-181.

Pena S, Santos FR, Bianchi NO, Bravi CM, Carnese RF, Rothhammer F, Gerelsaikhan T, Munkhtuja B and Oyunsuren T 
(1995) A major founder Y-chromosome haplotype in Amerindians. Nat Genet 11:15-16.

Perego UA, Achilli A, Angerhofer N, Accetturo M, Pala M, Olivieri A, Kashani BH, Ritchie KH, Scozzari R, Kong Q-P, et al. (2009) Distinctive Paleo-Indian migration routes from Beringia marked by two rare mtDNA haplogroups. Curr Biol 19:1-8.

Perego UA, Angerhofer N, Pala M, Olivieri A, Lancioni H, Kashani BH, Carossa V, Ekins JE, Gómez-Carballa A, Huber G, et al. (2010) The initial peopling of the Americas: A growing number of founding mitochondrial genomes from Beringia. Genome Res 20:1174-1179.

Ribeiro-dos-Santos AKC, Guerreiro JF, Santos SEB and Zago MA (2001) The split of the Arara population: Comparison of genetic drift and founder effect. Hum Hered 51:79-84.

Rickards O, Martinez-Labarga C, Lum JK, De Stefano GF and Cann RL (1999) mtDNA history of the Cayapa Amerinds of Ecuador: Detection of additional founding lineages for the native American populations. Am J Hum Genet 65:519-530.

Rodriguez-Delfin L, Santos SEB and Zago MA (1997) Diversity of the human Y chromosome of South American Amerindians: A comparison with Blacks, Whites and Japanese from Brazil. Ann Hum Genet 61:439-448.

Rojas W, Parra MV, Campo O, Caro MA, Lopera JG, Arias W, Duque C, Naranjo A, García J, Vergara C, et al. (2010) Genetic makeup and structure of Colombian populations by means of uniparental and biparental DNA markers. Am J Phys Anthropol 143:13-20.

Sala A, Argüelles CF, Marino ME, Bobillo C, Fenocchio A and Corach D (2010) Genetic analysis of six communities of Mbyá-Guaraní inhabiting northeastern Argentina by means of nuclear and mitochondrial polymorphic markers. Hum Biol 82:433-456.

Salzano FM and Callegari-Jacques SM (1988) South American Indians: A Case Study in Evolution. Clarendon Press, Oxford, $259 \mathrm{pp}$.

Salzano FM and Bortolini MC (2002) Evolution and Genetics of Latin American Populations. Cambridge University Press, Cambridge, $512 \mathrm{pp}$.

Santos FR, Hutz MH, Coimbra CEA, Santos RV, Salzano FM and Pena SDJ (1995) Further evidence for the existence of a major founder Y chromosome haplotype in Amerindians. Braz J Genet 18:669-672.

Santos SEB, Ribeiro-dos-Santos AKC, Meyer D and Zago MA (1996) Multiple founder haplotypes of mitochondrial DNA in Amerindians revealed by RFLP and sequencing. Ann Hum Genet 60:305-319.

Schmitt R, Bonatto SL, Freitas LB, Muschner VC, Hill K, Hurtado AM and Salzano FM (2004) Extremely limited mitochondrial DNA variability among the Aché Natives of Paraguay. Ann Hum Biol 31:87-94.

Schurr TG and Sherry ST (2004) Mitochondrial DNA and Y chromosome diversity and the peopling of the Americas: Evolutionary and demographic evidence. Am J Hum Biol 16:420439.

Schurr TG, Ballinger SW, Gan Y-Y, Hodge JA, Merriwether DA, Lawrence DN, Knowler WC, Weiss KM and Wallace DC (1990) Amerindian mitochondrial DNAs have rare Asian mutations at high frequencies, suggesting they derived from four primary maternal lineages. Am J Hum Genet 46:613623.
Seielstad M, Yuldasheva N, Singh N, Underhill P, Oefner P, Shen P and Wells RS (2003) A novel Y-chromosome variant puts an upper limit on the timing of first entry into the Americas. Am J Hum Genet 73:700-705.

Shimada I, Shinoda K-I, Farnum J, Corruccini R and Watanabe H (2004) An integrated analysis of pre-Hispanic mortuary practices. Curr Anthropol 45:369-402.

Shinoda K, Adachi N, Guillen S and Shimada I (2006) Mitochondrial DNA analysis of ancient Peruvian highlanders. Am J Phys Anthropol 131:98-107.

Silva Jr WA, Bonatto SL, Holanda AJ, Ribeiro-dos Santos AK, Paixão BM, Goldman GH, Abe-Sandes K, Rodriguez-Delfin L, Barbosa M, Pacó-Larson ML, et al. (2002) Mitochondrial genome diversity of Native Americans supports a single early entry of founder populations into America. Am J Hum Genet 71:187-192.

Silva Jr WA, Bonatto SL, Holanda AJ, Ribeiro-dos-Santos AK, Paixão BM, Goldman GH, Abe-Sandes K, Rodriguez-Delfin L, Barbosa M, Paçó-Larson ML, et al. (2003) Correction: Mitochondrial DNA variation in Amerindians. Am J Hum Genet 72:1346-1348.

Tamm E, Kivisild T, Reidla M, Metspalu M, Smith DG, Mulligan CJ, Bravi CM, Rickards O, Martinez-Labarga C, Khusnutdinova EK, et al. (2007) Beringian standstill and spread of Native American founders. PLoS One 2:e829.

The Y Chromosome Consortium (2002) A nomenclature system for the tree of human Y-chromosomal binary haplogroups. Genome Res 12:339-348.

Torres MM, Bravi CM, Bortolini MC, Duque C, Callegari-Jacques S, Ortiz D, Bedoya G, Groot de Restrepo H and Ruiz-Linares A (2006) A revertant of the major founder Native American haplogroup $\mathrm{C}$ common in populations from northern South America. Am J Hum Biol 18:59-65.

Torroni A, Schurr TG, Yang C-C, Szathmary EJE, Williams RC, Schanfield MS, Troup GA, Knowler WC, Lawrence DN, Weiss KM, et al. (1992) Native American mitochondrial DNA analysis indicates that the Amerind and the Nadene populations were founded by two independent migrations. Genetics 130:153-162.

Torroni A, Schurr TG, Cabell MF, Brown MD, Neel JV, Larsen M, Smith DG, Vullo CM and Wallace DC (1993) Asian affinities and continental radiation of the four founding Native American mtDNAs. Am J Hum Genet 53:563-590.

Toscanini U, Gusmão L, Berardi G, Amorim A, Carracedo A, Salas A and Raimondi E (2008) Y chromosome microsatellite genetic variation in two Native American populations from Argentina: Population stratification and mutation data. Forensic Sci Int Genet 2:274-280.

Toscanini U, Gusmão L, Berardi G, Gomes V, Amorim A, Salas A and Raimondi E (2011) Male lineages in South American native groups: Evidence of M19 traveling south. Am J Phys Anthropol 146:188-196.

Underhill PA, Jin L, Zemans R, Oefner PJ and Cavalli-Sforza LL (1996) A pre-Columbian Y chromosome-specific transition and its implications for human evolutionary history. Proc Natl Acad Sci USA 93:196-200.

Underhill PA, Jin L, Lin AA, Mehdi SQ, Jenkins T, Vollrath D, Davis RW, Cavalli-Sforza LL and Oefner PJ (1997) Detection of numerous $\mathrm{Y}$ chromosome biallelic polymorphisms by denaturing high-performance liquid chromatography. Genome Res 7:996-1005. 
Underhill PA, Passarino G, Lin AA, Shen P, Mirazón Lahr M, Foley RA, Oefner PJ and Cavalli-Sforza LL (2001) The phylogeography of $\mathrm{Y}$ chromosome binary haplotypes and the origins of modern human populations. Ann Hum Genet $65: 43-62$.

Vallinoto AC, Cayres-Vallinoto IM, Ribeiro Dos Santos ÂKC, Zago MA, Santos SE and Guerreiro JF (1999) Heterogeneity of Y chromosome markers among Brazilian Amerindians. Am J Hum Biol 11:481-487.

Vona G, Falchi A, Moral P, Calò CM and Varesi L (2005) Mitochondrial sequence variation in the Guahibo Amerindian population from Venezuela. Am J Phys Anthropol 127:361-369.

Ward RH, Salzano FM, Bonatto SL, Hutz MH, Coimbra CEA and Santos RV (1996) Mitochondrial DNA polymorphism in three Brazilian Indian tribes. Am J Hum Biol 8:317-323.

Weir BS (1996) The second National Research Council report on forensic DNA evidence. Am J Hum Genet 59:497-500.

Weir BS and Cockerham CC (1984) Estimating F-statistics for the analysis of population structure. Evolution 38:1358-1370.

Williams SR, Chagnon NA and Spielman RS (2002) Nuclear and mitochondrial genetic variation in the Yanomamo: A test case for ancient DNA studies of prehistoric populations. Am J Phys Anthropol 117:246-259.

Yang NN, Mazières S, Bravi C, Ray N, Wang S, Burley MW, Bedoya G, Rojas W, Parra MV, Molina JA, et al. (2010) Contrasting patterns of nuclear and mtDNA diversity in Native American populations. Ann Hum Genet 74:525-538.

Zegura SL, Karafet TM, Zhivotovsky LA and Hammer MF (2004) High-resolution SNPs and microsatellite haplotypes point to a single, recent entry of Native American Y chromosomes into the Americas. Mol Biol Evol 21:164-175.

\section{Internet Resources}

PASW Statistics 18, http://www.spss.com (June 10, 2011).

Pubmed, http://www.ncbi.nlm.nih.gov/pubmed/ (June 10, 2011).

Y Chromosome Haplotype Reference Database, http://www.yhrd.org/ (June 10, 2011).

Lewis MP (2009) Ethnologue: Languages of the World. $16^{\text {th }}$ edition. SIL International, Dallas, http://www.ethnologue.com/.

Associate Editor: Mara H. Hutz

License information: This is an open-access article distributed under the terms of the Creative Commons Attribution License, which permits unrestricted use, distribution, and reproduction in any medium, provided the original work is properly cited. 